\title{
Article \\ Experimental and Numerical Analysis of SMC Compression Molding in Confined Regions-A Comparison of Simulation Approaches
}

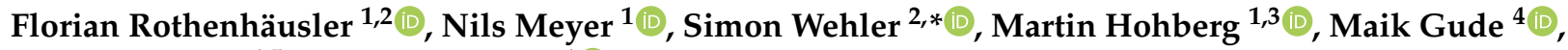 \\ Frank Henning ${ }^{1,5}$ and Luise Kärger ${ }^{1}$ (D)
}

check for

updates

Citation: Rothenhäusler, F.; Meyer, N.; Wehler, S.; Hohberg, M.; Gude, M.; Henning, F.; Kärger, L. Experimental and Numerical Analysis of SMC Compression Molding in Confined Regions-A Comparison of Simulation Approaches. J. Compos. Sci. 2022, 6, 68. https://doi.org/ $10.3390 /$ jcs6030068

Academic Editor: Francesco Tornabene

Received: 7 August 2021

Accepted: 9 February 2022

Published: 23 February 2022

Publisher's Note: MDPI stays neutral with regard to jurisdictional claims in published maps and institutional affiliations.

Copyright: (C) 2022 by the authors. Licensee MDPI, Basel, Switzerland. This article is an open access article distributed under the terms and conditions of the Creative Commons Attribution (CC BY) license (https:// creativecommons.org/licenses/by/ $4.0 /)$.
1 Karlsruhe Institute of Technology (KIT), Institute of Vehicle System Technology, 76131 Karlsruhe, Germany; florian.rothenhaeusler@uni-bayreuth.de (F.R.); nils.meyer@kit.edu (N.M.); martin.hohberg@simutence.de (M.H.); frank.henning@kit.edu (F.H.); luise.kaerger@kit.edu (L.K.)

2 Group Innovation, Volkswagen AG, 38442 Wolfsburg, Germany

3 SIMUTENCE GmbH, 76131 Karlsruhe, Germany

4 Institute of Lightweight Engineering and Polymer Technology (ILK), Technische Universität Dresden, 01307 Dresden, Germany; maik.gude@tu-dresden.de

5 Fraunhofer Institute for Chemical Technology, 76327 Pfinztal, Germany

* Correspondence: simon.wehler@volkswagen.de

\begin{abstract}
The compression molding process of sheet molding compound (SMC) is an economical manufacturing process for lightweight parts. However, molding defects, such as fiber matrix separation, and fiber re-orientation, may develop during the molding process in confined regions, such as ribs and bosses. Hence, the mechanical properties of the composite depend on the local fiber architecture. Consequently, this work compares the predictive capabilities of tensor-based and directly modeled process simulation approaches regarding compression force, fiber volume content and fiber orientation on the example of honeycomb structures molded from SMC. The results are validated by micro-computed tomography and thermal gravimetric analysis. The fiber orientation in the honeycomb varies between individual samples because a sheet molding compound is macroscopically heterogeneous and thus the fiber architecture is strongly influenced by random events. Tensor-based fiber orientation models can not reliably predict fiber volume content and fiber orientation in the part's thickness direction if there is a lack of scale separation. Therefore, directly modeled process simulations should be preferred in cases in which fiber length and mold dimensions prohibit scale separation. The prediction of fiber volume content is a difficult task and no simulation can predict the severity of fiber matrix separation precisely in all cases.
\end{abstract}

Keywords: sheet molding compound; thermal gravimetric analysis; micro-computed tomography; process simulation; honeycombs; fiber matrix separation

\section{Introduction}

The transition from conventional vehicles to battery electric vehicles creates new challenges for the structural design process. The new crash management system (CMS) has to overcome the missing substructure of the combustion engine with regard to crash safety and the increase in mass caused by the battery system by means of improved support structures.

One approach is the local reinforcement of metallic crash elements with fiber reinforced polymers (FRP), which offer high mass-specific stiffness and strength. The energy absorption capacity of the crash elements is an important factor here. For the specific energy absorption, honeycomb structures show a high potential. As crash elements, they are already being used by various car manufacturers and are mainly made of discontinuous fiber-reinforced polymers. An important advantage of discontinuous FRP are their low material and manufacturing costs, as well as the high freedom of design. The excellent mechanical 
properties of FRP are directly related to the fiber length, fiber volume fraction and the fiber orientation in the component. An increase in these properties up to a certain level while maintaining the complexity and design freedom of the manufacturing process would thus have a positive effect on the crashworthiness of the hybrid metal-FRP-CMS [1,2].

One possibility is the use of sheet molding compound (SMC), which has become a very attractive material in recent years, especially for exterior parts in the automotive industry. SMC consists of a thermosetting resin reinforced with chopped fibers and in most cases mineral fillers. SMC components are usually manufactured in a compression molding process, which allows the processing of long-fiber-reinforced polymers. Compared with injection-molded parts, compression-molded parts are superior in terms of increased strength and toughness due to the higher fiber length.

During the compression molding of SMC, the initial fiber architecture is changed and is influenced by process parameters, e.g., the initial charge position or the manufacturing process conditions. At first, research on local changes in microstructure was mainly focused on fiber length and orientation rather than changes in FVC, which is commonly known as fiber matrix separation (FMS). It develops if fibers are not transported homogeneously with the matrix during mold filling. As a result, fiber content becomes non-uniform, even when averaged over macroscopic volumes. This leads to a lower than nominal FVC along the flow path and at the flow front in particular [3]. In this process, FMS results from a balance of forces between suspended fibers, fibers and mold surface, the elastic deformation of the fibers, and hydrodynamic forces acting as a result of fluid flow [4-6]. Basic experiments have shown that FMS is also formed in flat, round or rectangular compression-molded stacks $[7,8]$ and depends, for instance, on the fiber-aspect ratio, the matrix viscosity [9] and the closing speed during production [10]. Usually, FMS is most pronounced in the top sections of ribs [11-13], which can be coupled with an increased fiber density in the rib base [14].

This fiber architecture has a direct influence on the mechanical behavior of the molded part. The effects of process parameters on the structural-mechanical component properties must therefore be mapped with a functional virtual process chain in order to create enhanced confidence in the class of discontinuous long-fiber-reinforced composites, as is already standard in metal processing with commercial software linking tools. Such a coupling has already been considered in short-fiber thermoplastic injection molding with a validation using a demonstrator and is also available for commercial use [15]. For the compression molding process of long-fiber-reinforced thermoplastics, Buck et al. [16] showed the effect of coupling process and structure simulation. Görthofer et al. [17] presented an approach for an integrated virtual process chain for SMC compression molding.

However, the base of any virtual process chain is a reliable and efficient process simulation, which is able to provide high-quality result data to map the material-specific characteristics of the specific material class. A brief overview of the state of research in fiber reorientation modeling is described below. Basically, a distinction is made between macroscopic models, which describe the fiber composite as a single-phase medium, and microscopic or mesoscopic approaches, which differentiate between fiber and matrix. Macroscopic models are used to predict the fiber orientation and pressure distribution in components and are already integrated in commercial software environments. Fiber orientation prediction started in 1922 with G. B. Jeffery's approach to Einstein's publication on the behavior of spherical particles in a liquid [18]. Jeffery extended Einstein's work [19] for ellipsoidal particles and described their rotation in a dilute Newtonian flow. The velocity field of the fluid is not influenced by the particle and the contact between particle and fluid is assumed to be perfect. This approach was extended by Folgar and Tucker, who developed a phenomenological model to predict the orientation distribution of fibers in concentrated suspensions [20]. Their derived model is regarded as the initial model for the prediction of fiber orientation in process simulation. Advani and Tucker [21] proposed the use of statistical moments of the fiber orientation distribution function (called fiber orientation tensors and denoted $\mathbf{A}$ here) to efficiently describe the orientation state in 
numerical models. Some experimental shortcomings, especially regarding the limitation of fiber length, have led to extended models by Wang et al. [22], Phelps et al. [23] and Tseng et al. [24]. These tensor-based models provide good results for FRP with fiber lengths smaller than the characteristic length of the component [25], i.e., if scale separation applies. This term refers to the assumption that the fiber architecture is a local state of material without any significant extension at the part scale. It may be violated if the fiber length is in the order of magnitude of geometrical features.

All macroscopic modeling approaches published to date are phenomenological and cannot detail the specific mechanics during fiber-fiber interaction. In highly concentrated fiber suspensions, however, fiber interactions are the dominant factor for modeling fiber re-orientation and distribution. For this reason, such methods seem to be of limited suitability for use in a virtual process chain for long-fiber-reinforced plastics with confined regions.

With simulation methods on the microscopic or mesoscopic level, fiber movements can be simulated for discretized fibers. In contrast to the phenomenological macroscopic fiber orientation models, modeling approaches on the microscopic scale allow a more precise approximation of the physical behavior [22,26-30]. At the micro level, different modeling approaches can be used. They can be roughly divided into particle-based methods, in which the polymer matrix and the fibers are treated as particles, or element-based methods, in which fibers are treated as particles and the matrix as a continuous medium. In contrast to particle-based methods, which are by nature two-way coupled, element-based simulations are often solved with one-way coupling. The feedback from the fiber motion on the fluid is computationally complex, but can be integrated in a general or refined way [31,32].

In this work, two direct element-based simulation methods with different coupling mechanisms between fiber and matrix and two macroscopic models are investigated for the process simulation of the SMC compression molding process. Furthermore, they are tested for their predictive accuracy using a real structure manufactured with different process conditions, based on fiber orientation, distribution, fiber matrix separation, compression forces and short-shot flow front.

An important factor for this comparison is the reproducibility of fiber orientation and distribution under real conditions, especially in complex three-dimensional structures. To the authors' knowledge, previous works did not address this problem or only in geometrically simple structures, where the fiber length and component dimensions are at least one order of magnitude apart. Instead, this study examines the filling of a complex honeycomb structure with an SMC whose fiber length is in the same order of magnitude as the part's geometric features. The process simulations are compared and validated by their prediction of the compression force, fiber volume content and fiber orientation inside a complex ribbed honeycomb structure.

\section{Materials and Specimen Production}

The material processed is an SMC named HUP EJ 43529 produced by Polynt Composites Germany $\mathrm{GmbH}$, Germany. It contains $54 \mathrm{wt} \%$ glass fiber bundles, $36.8 \mathrm{wt} \%$ vinyl ester resin and $9.2 \mathrm{wt} \% \mathrm{CaCO}_{3}$ (measured by thermal gravimetric analysis (TGA) of SMC plates with $95 \%$ mold coverage). Therefore, the nominal fiber volume content $\phi_{\mathrm{n}}$ is approximately $36.6 \%$. Glass fibers are $50 \mathrm{~mm}$ long, have a diameter of $20 \mu \mathrm{m}$ and are assembled in bundles comprising about 560 individual fibers.

The honeycomb structure is a demonstrator for a complex rib structure that will be molded into a metal profile which serves as an automotive CMS. The mold cavity features two honeycomb structures with different wall thicknesses and draft angles (see Figure 1a). The different geometries are chosen to determine the influence of rib width on the development of fiber matrix separation (FMS) and molding defects, such as pores. For this study, only the results of the thick honeycomb walls are considered. The influence of the geometry (i.e., different wall thicknesses) on fiber architecture is not a focus of this work. 
The thick honeycomb consists of walls with $2.5 \mathrm{~mm}$ thickness at the top (see Figure 1c) and a draft angle of $2^{\circ}$. The base plate has an area of $310 \mathrm{~mm}$ by $310 \mathrm{~mm}$ and is $2 \mathrm{~mm}$ thick.

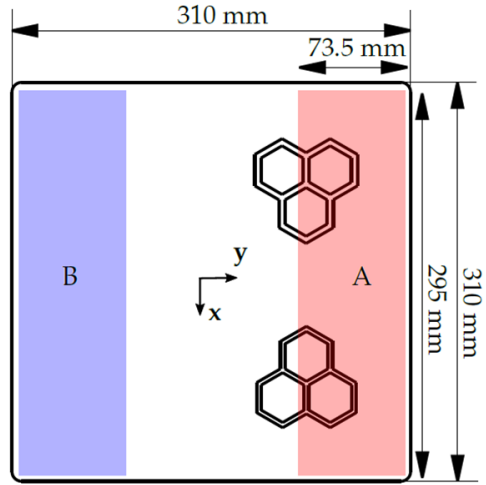

(a) Cavity

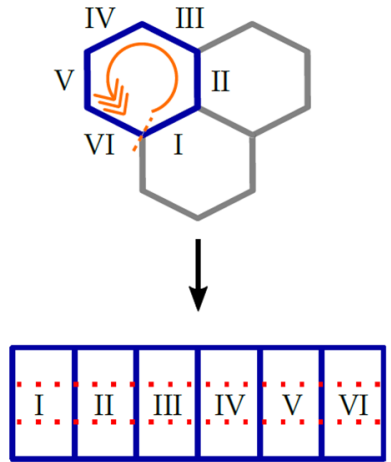

(b) Coupon labeling

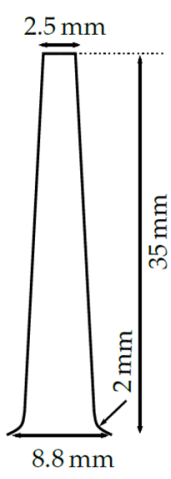

(c) Cross section

Figure 1. Geometry and specimen labeling. (a) The thick honeycomb is located at the top, and the thin honeycomb is located at the bottom in this representation. The shaded areas show where the initial SMC charge is placed. The red area indicates the charge position in Configuration A, whereas the blue area shows the charge position in Configuration B. (b) The coupon (blue) of the thick honeycomb is mentally unrolled anti-clockwise. This arrangement is used for the presentation of $\mu \mathrm{CT}$ scans, thermal gravimetric analysis (TGA) results and predictions of process simulations. The red dotted lines indicate the positions where the walls are cut into smaller specimens for TGA. (c) Cross section of walls that form the thick honeycomb.

The compression molding is conducted on a double-column press of type RSP 160.42 SZ by Röcher GmbH \& Co. KG Maschinenbau, Germany. To investigate the influence of different initial charge positions, two process configurations named Configuration $\mathrm{A}$ and Configuration B are specified. The initial charge position of Configuration A is underneath the honeycombs, whereas the initial charge is positioned opposite to the honeycombs in Configuration B (see Figure 1a). The process parameters are summarized in Table A1.

For the investigation, only one of three honeycomb cells, a coupon with six walls, is used. A coupon consisting of these six walls is preferred because the individual walls can be shown side by side, thus giving a better overview of the 3D fiber architecture. A pre-trial showed that this specific cell reliably contained the defects, which are the focus of this work, and it is filled regularly to obtain equivalent samples. Figure $1 \mathrm{~b}$ shows the coupon and the representation of its walls side by side. The dotted red lines indicate the positions where the walls are cut into smaller specimens for TGA.

\section{Experimental Methods}

\subsection{Thermal Gravimetric Analysis}

The fiber volume content (FVC) $\phi$ of specimens is determined according to the procedure B of EN ISO 1172:1998 [33]. It is calculated employing the densities of glass fibers $\rho_{\mathrm{f}}=2.6 \mathrm{~g} \mathrm{~cm}^{-3}$, vinyl ester matrix $\rho_{\mathrm{m}}=1.13 \mathrm{~g} \mathrm{~cm}^{-3}$ and calcium carbonate $\rho_{\mathrm{CaCO}_{3}}=$ $2.71 \mathrm{~g} \mathrm{~cm}^{-3}[34,35]$.

The fiber matrix separation index (FMSI) is introduced as a means to quantify the overall peculiarity of fiber matrix separation in the honeycomb. It is the average of the normalized difference between the experimentally found FVC in a specimen $\phi_{i}$ and the nominal FVC $\phi_{\mathrm{n}}$. The volume weighting $v_{i}$ takes the different volumes of the specimens into account. Thus, the FMSI is calculated by

$$
\mathrm{FMSI}=\frac{1}{v_{\mathrm{S}}} \sum_{i=0}^{N} v_{i} \frac{\left|\phi_{i}-\phi_{\mathrm{n}}\right|}{\phi_{\mathrm{n}}},
$$


where $v_{\mathrm{S}}$ denotes the sum over all weighting factors $v_{i}$. The specimen partition presented in Figure $1 b$ is a trade-off between sufficient spatial resolution and reasonable workload. Three repetitions are conducted for each process configuration.

\subsection{Matrix Rheology}

The dynamic matrix viscosity is characterized by small-amplitude oscillatory shear (SAOS) in a plate-plate geometry with a diameter of $25 \mathrm{~mm}$. The rheological measurements are conducted on a Haake Mars III by Thermo Fisher Scientific Inc., United States. The matrix material is stored for three weeks at room temperature in a closed container before the rheological measurements. This time is similar to the maturation time of the SMC before delivery and subsequent compression molding.

\subsection{SMC In-Mold Rheology and Friction at the Tool Surface}

The reliable material parameter identification is one of the most important steps for the process simulation, especially considering the prediction of press forces. For this reason, a near-process characterization was carried out employing a press rheometer on a Dieffenbacher COMPRESS PLUS DCP-G 3600/3200 AS hydraulic press by Dieffenbacher Holding $\mathrm{GmbH} \& \mathrm{Co}$. KG., Germany. A press rheometer is a simple rectangular plate tool, which is equipped with several pressure sensors. The pressure sensors are used both to measure the local pressure and to identify the position of the current flow front. Such a tool was initially developed by Castro and Griffith [36] and improved by Dumont et al. [37-39], as well as Hohberg et al. [40-42].

For the press rheometer trials, a rectangular cavity of $800 \mathrm{~mm} \times 450 \mathrm{~mm}$ and 9 pressure sensors were used at the Fraunhofer Institute for Chemical Technology (ICT), Pfinztal, Germany. The molding trials were performed with the standard temperatures given by the data sheet. The initial charge coverage varied between $37.5 \%$ (300 $\mathrm{mm} \times 450 \mathrm{~mm})$ and $75.0 \%(600 \mathrm{~mm} \times 450 \mathrm{~mm})$. For the closing speed profile, experimental trials with constant closing speeds $\left(v=1.0 \mathrm{~mm} \mathrm{~s}^{-1}, 0.5 \mathrm{~mm} \mathrm{~s}^{-1}, 0.4 \mathrm{~mm} \mathrm{~s}^{-1}, 0.3 \mathrm{~mm} \mathrm{~s}^{-1}\right.$ and $\left.0.2 \mathrm{~mm} \mathrm{~s}^{-1}\right)$, as well as constant deformation rates $\left(D=0.10 \mathrm{~s}^{-1}, 0.05 \mathrm{~s}^{-1}\right.$ and $\left.0.01 \mathrm{~s}^{-1}\right)$, were conducted.

\subsection{Micro-Computed Tomography}

Micro-computed tomography $(\mu \mathrm{CT})$ is a non-destructive testing method which allows the analysis of a sample's internal material structure by reconstructing a 3D object from $X$-ray images. The resolution of the $3 \mathrm{D}$ object, the so-called voxel, depends on the distance between specimen and X-ray source, or rather the size of specimen and detector. For fiber orientation analysis of individual fibers, voxel size needs to be smaller than the fiber diameter. In contrast, the orientation analysis of fiber bundles only requires a resolution that is smaller than the fiber bundle diameter, as fibers tend to remain assembled in bundles during mold filling [43]. Table A3 gives an overview about the parameters used for the $\mu \mathrm{CT}$ of coupons.

\section{Numerical Methods}

All numerical models assume negligible curing [44-46] and a planar isotropic initial fiber orientation state, because fiber bundles fall irregularly onto the conveyor belt during SMC prepreg production. Besides the characterizations performed within this work, the SMC viscosity was also characterized by Toray Engineering Co., Ltd., Japan via press rheometry and its viscosity is modeled via a Cross-Andrade model [47]. During the rheological characterization of the SMC by Toray, there was no differentiation between the contributions of viscous forces and friction forces. Thus, the viscosity measurement by Toray includes the friction between SMC and press rheometer. This can be interpreted as treating the friction and viscosity in a combined way, but it does not allow for a separation of effects due to friction and the material itself, which can lead to incorrect results in cases that are different to the characterization conditions. Still, the characterization by Toray was 
used because it fits the material model used in 3D TIMON. The resulting material data are used as input for MOLDEX3D and 3D TIMON (see Appendix Table A2).

\subsection{Macroscopic Process Simulation}

Within this investigation, two commercial macroscopic process simulation tools are used: MOLDEX3D by CoreTech System Co., Ltd. and MOLDFLOW by Autodesk, Inc. In both tools, the gradients of the velocity field are used to calculate the fiber orientation evolution with one-phase macroscopic models, assuming that fibers and matrix have the same velocity and, therefore, that no fiber matrix separation can occur. In the models applied in this work, the fiber orientation does not affect the flow, as no anisotropic viscosity models are used. Thus, the fiber orientation calculation could be considered a post-processing step.

\subsubsection{MOLDEX3D 2020}

The part geometry and compression zone are modeled with triangular prisms with an edge length of $1.5 \mathrm{~mm}$. The part is modeled by 17 elements over its thickness, while the compression zone is discretized by 50 elements in the compression direction. Overall, this results in 2,322,404 and 4,953,872 mesh elements in the part and compression zone, respectively. The compression profile of the press is prescribed as input for MOLDEX3D with a maximum compression force of $1500 \mathrm{kN}$. The friction coefficient for the contact between SMC and mold is set to 0 . This seems appropriate, considering that the viscosity characterized by Toray already includes the friction between SMC and press rheometer. The iARD-RPR model and IBOF-closure are used for the fiber orientation analysis [48,49]. The coefficients for the iARD-RPR model are $C_{\mathrm{I}}=0.1, C_{\mathrm{M}}=1$ and $\alpha=0.9$, following [50].

\subsubsection{MOLDFLOW 2021}

For the simulation, the full geometry is used, since MOLDFLOW offers no symmetry boundary condition. The mold cavity and therefore the compression zone is modeled with tetrahedrons with an edge length of $3 \mathrm{~mm}$ and at least 26 elements over the part thickness, which results in 2,144,015 tetrahedrons elements for the cavity. For the press displacement, a closing speed profile as well as maximum compression force of $1500 \mathrm{kN}$ were given as input, which is identical to the press profile applied in MOLDEX3D. The SMC was characterized for this study, as described in Section 3.3 with the resulting rheological parameters and friction parameters given in Table A5. For the fiber orientation analysis, the Reduced Strain Closure (RSC) Model is used together with the Orthotropic 3 closure [51,52]. The coefficient for the RSC model is $C_{i}=0.1$ and the RSC factor is 0.9 according to the MOLDEX3D simulation settings.

\subsection{Direct Simulation Models at Microscale and Mesoscale}

The term direct simulation models is used in this work to classify methods that directly model the motion of individual fiber particles in a suspension. Here, fibers are approximated by rods or spheroids and flexible fibers are represented by connected rods, spheres or spheroids. The fibers might interact through hydrodynamic, elastic, lubrication and friction forces with the surrounding fluid and each other [22,26-29]. The effect of fibers on the fluid field can be incorporated, for example, following the work of [31]. One method employed in this work is based on the process simulation software 3D TIMON COMPOSITEPRESS ${ }^{\mathrm{TM}}$ by Toray Engineering Co., Ltd., which does not account for interactions between fibers. Another method is based on the approach by [32], which takes fiber-fiber interactions and the effect of fibers on the fluid field into account. The resulting bundle positions of the direct simulation models are exported to VTK and mapped to an evaluation mesh using a ParaView filter (the filter is available at https://github.com/nilsmeyerkit/paraview_map_ lines, accessed on 14 February 2022) to compute fiber orientation tensors and fiber volume fractions from the line elements. The evaluation mesh exactly represents the cells that are used as coupons during the thermal gravimetric analysis and enables the comparison between experimental results and the macroscopic models. 


\subsubsection{D TIMON 10 R6.0.1}

The Direct Fiber Simulation (DFS), which is a feature of 3D TIMON [53,54], is used to simulate the motion of long fibers during SMC compression molding. The fiber movement is calculated in a post-processing step after a classical macroscopic process simulation with 3D TIMON COMPOSITEPRESS ${ }^{\mathrm{TM}}$ and fiber nodes move with the pre-computed velocity field [55]. This results in a one-way coupling, which means that fiber movement is dictated by the flow field but the flow field is not influenced by the presence or orientation of fibers [56]. Anisotropic flow behavior due to fiber orientation is neglected and fiber-fiber interactions are not considered [14]. Thus, the need to list neighboring fibers and to calculate interaction forces between neighboring fiber segments vanishes. Thereby, the computational effort is reduced immensely.

Fibers are modeled as rods that are connected by nodes which function as joints. During the simulation, joint nodes are moved independently from each other with the polymer flow, whereby a new temporary node position

$$
\hat{\mathbf{x}}_{i}^{n+1}=\mathbf{x}_{i}^{n}+\mathbf{u}_{i}^{n} \mathrm{~d} t,
$$

is calculated. Here, $\mathbf{x}_{i}^{n}$ is the position of node $i$ at time step $n, \mathbf{u}_{i}^{n}$ the velocity of the surrounding fluid around node $i$ at time step $n$ and $\mathrm{d} t$ the time increment. This inevitably leads to an unrealistic elongation of fibers during the filling of complex geometries. Therefore, the DFS-algorithm continuously checks the length of each rod in each time step. Once an elongation threshold is exceeded, the temporary node positions are adjusted with a regularization scheme $\left(\hat{\mathbf{x}}_{i}^{n+1} \rightarrow \mathbf{x}_{i}^{n+1}\right)$ to maintain a constant fiber length [55].

Contrary to the other methods employed in this work, only the mold half containing the thick honeycomb is modeled to reduce the calculation run-time. This is deemed acceptable because the problem is quasi-symmetric and minor geometrical differences between thick and thin honeycomb hardly have an influence on the resulting flow field. Furthermore, this is favorable because in this study fibers are generated per unit volume of the initial charge. Thus, the number of fibers simulated and therefore calculation run-time were reduced. The part geometry and compression zone were modeled with a $3 \mathrm{D}$ voxel mesh with an edge length of $1.2 \mathrm{~mm}$ in $x$-, $1.2 \mathrm{~mm}$ in $y$ - and $0.7 \mathrm{~mm}$ in $z$-direction, respectively. Additionally, the mesh of the cavity around the part was refined with a 3D voxel mesh with an edge length of $1.2 \mathrm{~mm}$ in $x$-, $1.2 \mathrm{~mm}$ in $y$ - and $0.2 \mathrm{~mm}$ in $z$-direction. Overall, this results in 1,066,411 mesh elements for the cavity (see also Table A6 for computational parameters). The fibers are modeled with a length of $50 \mathrm{~mm}$ and 20 segments per fiber. A total of 145,130 fibers was generated with 2,902,600 fiber segments.

Contrary to the deformation mechanism reported by Barone and Caulk [57,58], the SMC/BMC-module of 3D TIMON assumes a no-slip boundary condition at the mold surface [47]. This results in high shear stresses and flow kinematics that do not match experimental results. Using the original compression force in the force-controlled compression phase would result in unrealistic long compression times. Hence, the maximum compression force was set to $10^{5} \mathrm{kN}$, asserting that the simulation follows the velocity profile and fits the compression time of the compression molding trials (see Section 5.3). This approach appears reasonable because the compression force has little influence on the development of the fluid velocity field, except for the velocity profile in the thickness direction of the SMC stack. The compression speed profile can only be modeled by a series of constant velocities. Therefore, the compression profile of the actual press data can only be approximated and it should be mentioned that jumps or discontinuities in the velocity profile are nonphysical.

\subsubsection{Direct Bundle Simulation}

Direct Bundle Simulation (DBS) is an approach to directly model SMC processing at mesoscale and is implemented with multiple custom subroutines in Simulia ABAQUS [32]. DBS uses the observation that fiber bundles typically stay intact during the compression molding of SMC [59-61]. Thus, the DBS approach treats hundreds of fibers in a bundle as 
a common instance and therefore drastically reduces the amount of suspended objects in the direct simulation. This enables the accurate prediction of bundle architectures on the component level [32].

The matrix motion is computed based on mass balance and momentum balance, which are solved with a Coupled Eulerian-Lagrangian framework in ABAQUS by operator splitting [62]. This technique enables the large deformation of the polymer and contact with Lagrangian rigid body mold surfaces. The matrix is modeled as a Newtonian isotropic fluid and no heat transfer is considered in this example. However, the incorporation of coupling with the bundle motion renders an overall anisotropic flow behavior. Due to the explicit solving scheme, a weakly compressible equation of state is utilized to model quasi-incompressible behavior. The interaction between both tool surfaces and SMC matrix is modeled with a hard normal contact and a hydrodynamic friction according to

$$
\tau=-\lambda\left(\frac{\left|v_{\mathrm{s}}\right|}{v_{0}}\right)^{m-1} v_{\mathrm{s}},
$$

with the relative velocity at the mold surface $v_{\mathrm{S}}$, the friction coefficient $\lambda$, power-law coefficient $m$ and reference velocity $v_{0}$. It is motivated by a thin lubrication layer of heated matrix at the mold surface [57].

The upper and lower mold surfaces are extracted from the CAD model of the part, placed at an initial distance of $12 \mathrm{~mm}$ and are meshed with rigid body elements of $2 \mathrm{~mm}$ average edge length. The lower mold remains fixed, while the upper tool is either controlled by a virtual press controller mimicking the press profile (Configuration $B$ ), or subjected to a constant force (Configuration A). Configuration A is simulated with a constant compression force, because the press comes effectively to a stop after reaching the stack and proceeds in a force-controlled mode in the trials with this configuration. The cavity is meshed with $1 \mathrm{~mm} \times 1 \mathrm{~mm} \times 1 \mathrm{~mm}$ Eulerian elements in the honeycomb area and $2.5 \mathrm{~mm} \times 2.5 \mathrm{~mm} \times$ $1 \mathrm{~mm}$ elements in the planar sections (see also Table A6 for computational parameters). Fiber bundles are represented by one-dimensional truss elements with $2.5 \mathrm{~mm}$ length and thus behave like threads. They may bend, but not present any mechanical resistance to bending. The total amount of truss elements is prescribed by the fiber volume fraction assuming 560 fibers per bundle with $20 \mu \mathrm{m}$ diameter each and results in an equivalent bundle diameter of $0.24 \mathrm{~mm}$. The exact amount varies slightly between individual initial bundle architectures due to the generation procedure. Furthermore, bundle elements are idealized as frictionless contact with other bundles, as well as the mold surface. The interaction between fiber bundles and the fluid phase is implemented with numerous subroutines which compute a body force on bundles based on the velocity relative to the surrounding fluid field $\Delta \mathbf{v}$. This hydrodynamic force on a bundle segment $j$ is computed as

$$
\mathbf{F}_{\mathrm{h}}^{(j)}=6 \pi \eta R\left(k_{\mathrm{d}} \Delta \mathbf{v}+k_{1}\|\Delta \mathbf{v}\| \mathbf{q}\right)
$$

with viscosity $\eta$, bundle radius $R$ and an orthogonal direction $\mathbf{q}$. The factors $k_{\mathrm{d}}$ and $k_{1}$ are drag and lift coefficients that depend on the segment aspect ratio and orientation of the bundle [32]. The weighted hydrodynamic forces are used to apply an opposed body force on the fluid phase that ensures a force equilibrium and effectively generates a generally anisotropic flow.

Thus, this approach allows the evaluation of fiber matrix separation, the computation of bundle curvature and an accurate prediction of the fiber architecture. In comparison with 3D TIMON, it accounts for fiber-fiber interactions and the effect of fibers on the flow. However, short-range lubrication between fiber bundles, as in [63], is not considered here.

The results of DBS are influenced by the fiber bundle architecture in the initial SMC stack. Thus, the simulation is run with three different initial fiber bundle architectures in each configuration to estimate the scatter due to different random realizations in the initial stack. 


\section{Experimental Results}

\subsection{Matrix Rheology}

The viscosity curve of the matrix shows that the matrix exhibits pronounced shear thinning at higher shear rates (see Figure 2). This behavior is typical for filled polymer systems, polymer melts and polymer solutions [64]. On the one hand, the number of entanglements between neighboring oligomers decreases with increasing shear rate. On the other hand, connections between oligomers and filler particles, as well as connections among filler particles themselves are lost. During frequency sweeps in the nonlinear regime, slip occurs between the plate geometry and the VE matrix at higher shear rates due to the high viscosity of the filled matrix. Hence, no reliable data of the shear thinning behavior are recorded. However, the deformation rates during compression molding of the specific case considered in this work are below $10 \mathrm{~s}^{-1}$. Subsequently, the VE-matrix is modeled as a Newtonian fluid without temperature dependence in the Direct Bundle Simulation. According to Figure 2, the zero shear viscosity of the matrix is approximately 25,000 Pa s which is used as the input parameter for DBS.

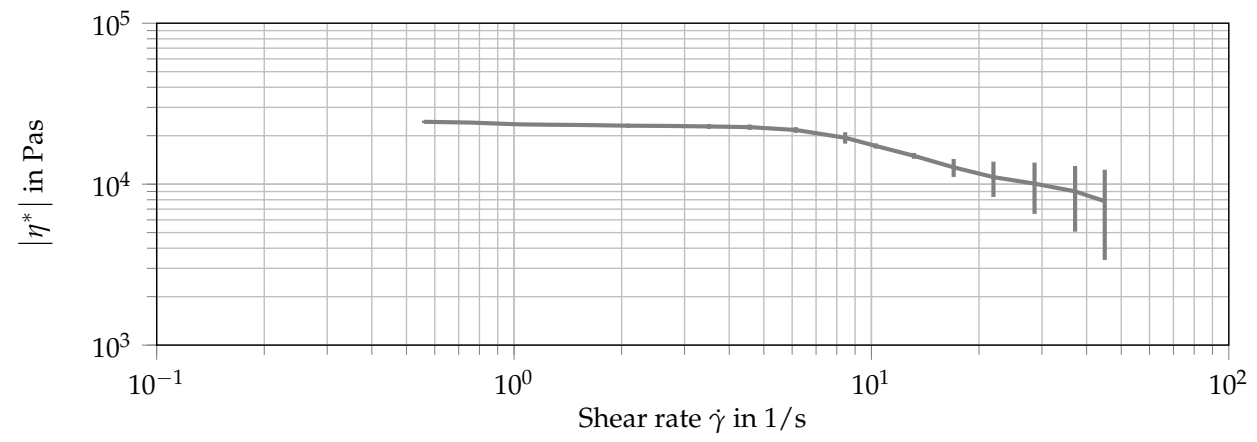

Figure 2. Average of the norm of complex dynamic viscosity $\left|\eta^{*}\right|$ of three frequency sweeps vs. shear rate $\dot{\gamma}$ of the VE matrix at $T=25^{\circ} \mathrm{C}$.

\subsection{SMC In-Mold Rheology and Friction at the Tool Surface}

With these experimental data from Section 3.3, the parameterization for the lubrication layer and its friction parameters is carried out as described by Hohberg et al. [40-42]. Therefore, an analytical stress equation, considering the rheological as well as the friction stresses, is fitted to the different experimental molding trials pressure measurements. Here, the data are fitted to the Cross-Andrade model for the effective viscosity

$$
\eta=\frac{\eta_{0}}{1+\left(\frac{\eta_{0} \dot{\gamma}}{\tau^{*}}\right)^{1-n}} \quad \text { with } \quad \eta_{0}=B \exp \left(\frac{T_{\mathrm{b}}}{T}\right)
$$

with the shear rate $\dot{\gamma}$, zero shear viscosity $\eta_{0}$, power-law coefficient $n$, critical shear stress $\tau^{*}$, temperature $T$, and data-fitting coefficients $B$ and $T_{\mathrm{b}}$. The slip velocity, respectively, the friction, is modeled as

$$
v_{\mathrm{S}}=\frac{\alpha_{\mathrm{w}}}{1+\left(\frac{\tau_{\mathrm{c}}}{\tau_{\mathrm{w}}}\right)^{10}} \tau_{\mathrm{w}}^{m}
$$

with $\tau_{\mathrm{w}}$ the wall shear stress, the critical wall shear stress $\tau_{\mathrm{c}}$ and the slip coefficient $\alpha_{\mathrm{w}}$. The resulting fitted values for all these model parameters are given in Table A5. Equivalently, the parameters of Equation (3) are determined.

An exemplary fitting result for three representative pressure sensors (S1 at $147 \mathrm{~mm}$ from tool edge, S2 at $249 \mathrm{~mm}$ and S3 at $451 \mathrm{~mm}$ ) for an 50\% initial charge coverage and a closing speed of $2.5 \mathrm{~mm} \mathrm{~s}^{-1}$ is given in Figure 3 to illustrate the fitting quality. 


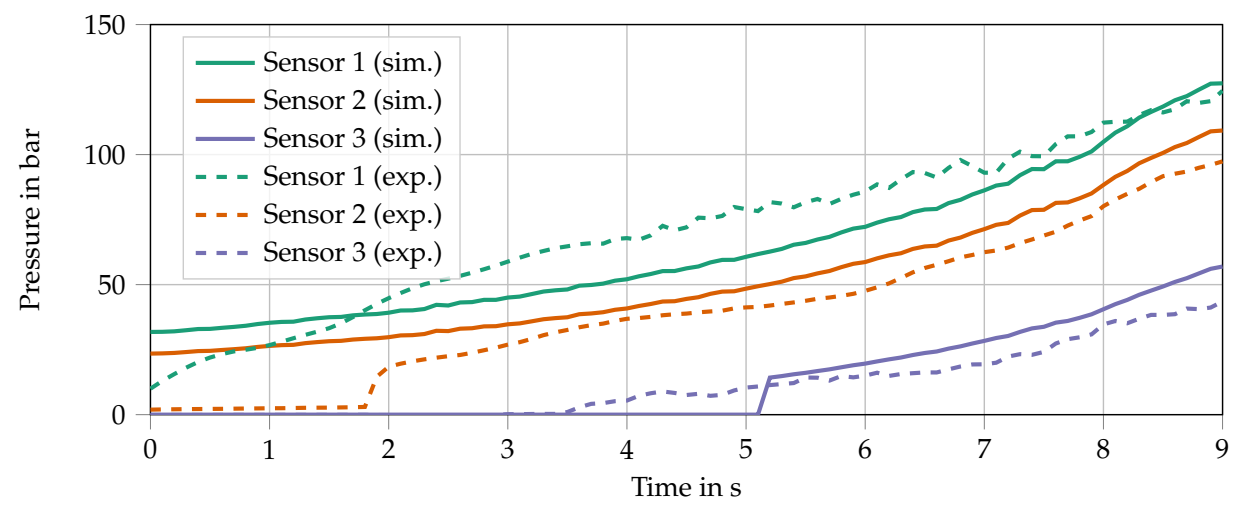

Figure 3. Exemplary fitting results of the predicted local stresses based on viscosity and friction stresses and comparison with the measured pressure from the rheological molding trials.

\subsection{Compression Profile}

The press data of parts molded with Configuration A show that the compression force varies significantly between successive moldings after reaching the maximum compression force (see Figure 4). Thereby, the force drops by up to $300 \mathrm{kN}$. The velocity profile shows that the press cannot maintain the programmed closing speed of $10 \mathrm{~mm} \mathrm{~s}^{-1}$ upon contact with the SMC charge. Interestingly, the compression force does not reach its maximum value of $1500 \mathrm{kN}$ at this point. Here, the upper mold almost comes to a complete stop at approximately $8 \mathrm{~s}$, which might be caused by the grip that the insert with its rib structure exerts on the stack. Then, the compression speed increases again for a short moment and reaches up to $15 \mathrm{~mm} \mathrm{~s}^{-1}$. Afterwards, the velocity drops to roughly 3 to $5 \mathrm{~mm} \mathrm{~s}^{-1}$ and decreases slowly from there on until the mold is closed completely.

The press data of parts molded with Configuration B (see Figure 4) show similar characteristics. The difference in compression force between successive moldings after reaching the maximum compression force is as large as $400 \mathrm{kN}$. Similarly to the press data of Configuration A, the velocity profile of Configuration B shows that the press cannot maintain the programmed closing speed of $10 \mathrm{~mm} \mathrm{~s}^{-1}$ upon contact with the SMC charge. Again, the compression force does not reach its maximum value of $1500 \mathrm{kN}$ at this point. Here, the upper mold does not stop completely. Instead, the velocity drops to roughly 3 to $5 \mathrm{~mm} \mathrm{~s}^{-1}$. Then, the compression speed increases again for a short moment and reaches up to $15 \mathrm{~mm} \mathrm{~s}^{-1}$. Afterwards, the velocity drops to roughly 1 to $2 \mathrm{~mm} \mathrm{~s}^{-1}$ and decreases slowly from there on until the mold is closed completely.

\subsection{Fiber Orientation}

The reproducibility of fiber orientation states is assessed by scanning the back wall of three identical trials that are molded with process Configuration A. The walls are extracted from the identical location. Figure $5 \mathrm{a}-\mathrm{c}$ show the three walls side by side. The same volume of each wall is analyzed with a set of evaluation meshes. The evaluation meshes are $2 \mathrm{~mm}$ thick in $\mathrm{y}$-direction and $18 \mathrm{~mm}$ long in $\mathrm{x}$ - and z-direction, which are the directions in the plane of the walls. Each evaluation mesh has the same total size but the number of cells per evaluation mesh is different. Thus, only the cell size and number of cells varies in the in-plane directions (see Figure $5 \mathrm{~d}, \mathrm{e}$ ). Cells located at the same position are compared regarding the fiber orientation components $A_{\mathrm{xx}}, A_{\mathrm{yy}}$ and $A_{\mathrm{zz}}$. The standard deviation of respective components is plotted as a function of the number of cells in Figure 6. 

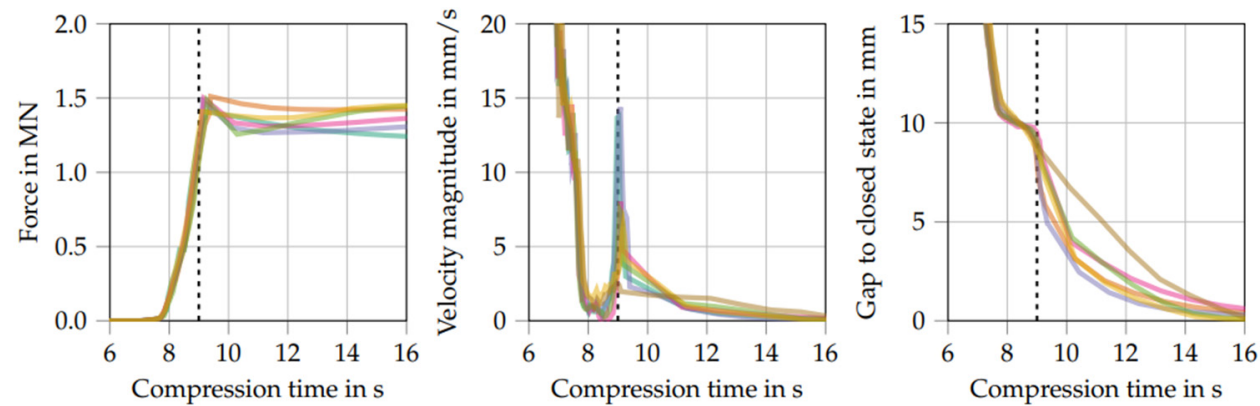

(a) Configuration $\mathrm{A}$
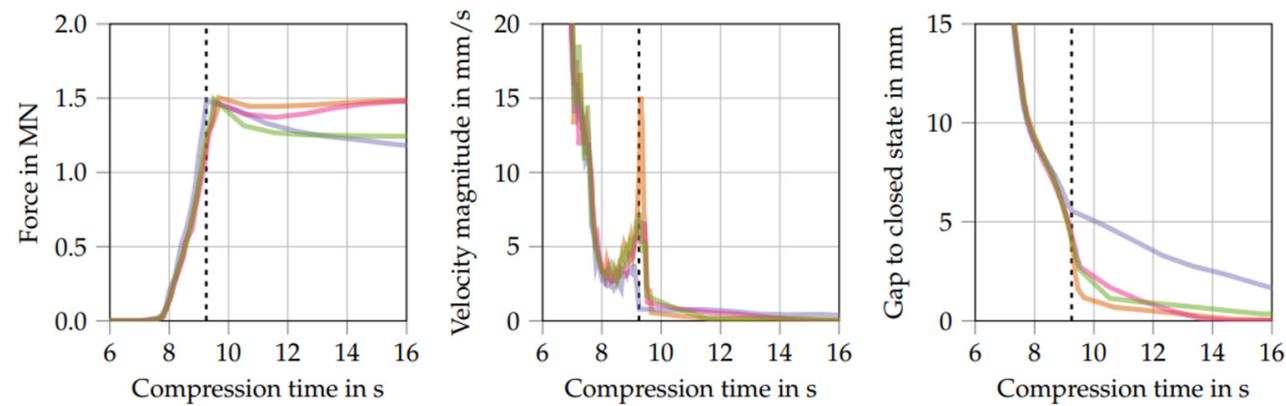

(b) Configuration B

Figure 4. Press data from several parts molded in Configurations A and B. The dashed lines indicate the switch from displacement control to force control.

A way to assess the reproducibility of a quantity is to compare its standard deviation (SD) to the standard deviation of a continuous uniform distribution (CUD). If the two standard deviations are approximately the same, this suggests that the variable depends on random processes of equal probability rather than systematic processes. The standard deviation of a CUD is

$$
\sigma(X)=\frac{b-a}{2 \sqrt{3}},
$$

with random variable $X$ that is uniformly distributed on an interval between lower limit $a$ and upper limit $b$ [65]. The lower and upper limit for the out-of-plane orientation $A_{\mathrm{yy}}$ are set to 0 and 0.15 , respectively. This appears reasonable because the fiber bundles are significantly longer than the wall thickness. Subsequently, the lower and upper limit for the in-plane orientations $A_{\mathrm{xx}}$ and $A_{\mathrm{zz}}$ are set to 0 and 0.85 , respectively. The standard deviation of a random variable $X$ uniformly distributed yields 0.245 for the in-plane and 0.043 for the out-of-plane fiber orientation components, respectively.

The averages of the standard deviations of the in-plane orientations $A_{\mathrm{xx}}$ and $A_{\mathrm{zz}}$ are roughly $46.9 \%$ and $38.3 \%$ of the standard deviation of a CUD. Here, the standard deviations scatter strongly. This trend increases for an increased number of cells per evaluation mesh. There is no correlation between cell position and standard deviation. Thus, the standard deviation of individual cells seems to be random as well. The average of the standard deviation of the out-of-plane orientation $A_{\mathrm{yy}}$ is approximately $64.1 \%$ of the standard deviation of a CUD. In conclusion, there are strong indications that the fiber orientation states in the walls are determined by random events rather than by systematic processes. 


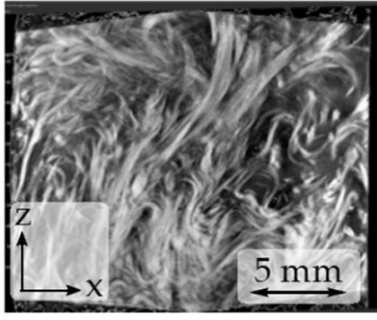

(a)

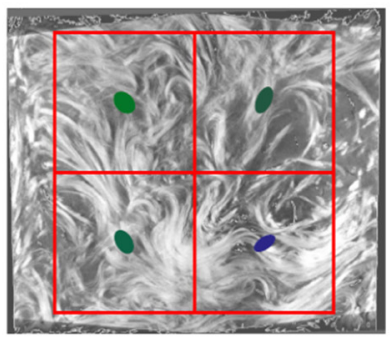

(d)

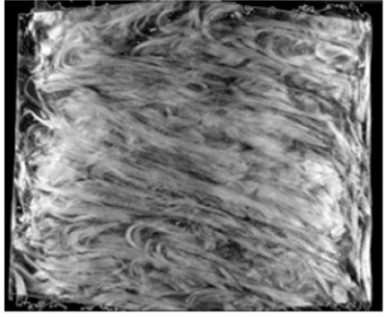

(b)

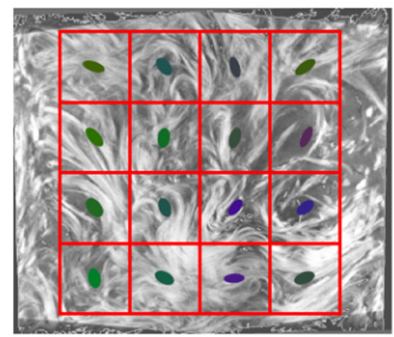

(e)

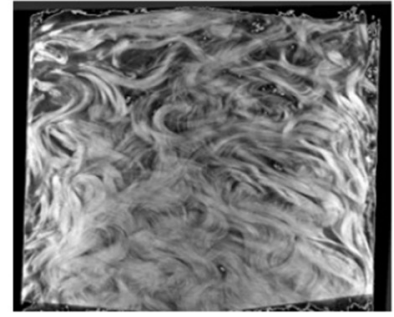

(c)

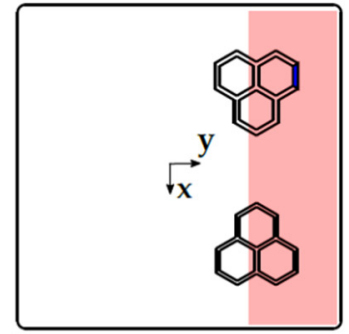

(f)

Figure 5. CT scan of the back wall of three identical trials molded with process Configuration A, (a-c). All three show different fiber orientation states even though they are molded from the same material, with the same process conditions and extracted from the same location. Evaluation meshes with 4 cells (d) and 16 cells (e). These are used for the fiber orientation analysis of the walls in (a-c). The total volume and position of the evaluation mesh is the same for each number of cells. The position of the walls shown in $(\mathbf{a}-\mathbf{c})$ is highlighted in blue in (f). The red area shows the position of the initial charge in Configuration A.

The interpretation of these results is that due to a lack of scale separation, each molding represents only a single realization of random processes. Thus, the different initial microstructure in each SMC stack results in varying fiber orientation states in the honeycomb. Of course, the comparison of fiber orientation states via fiber orientation tensors is complicated once FMS leaves only few fiber bundles in the volume under consideration. In conclusion, the evaluation of fiber orientation states and the validation of process simulations via an orientation tensor is questionable if it depends only on a few entities whose existence and orientation are determined by random processes.
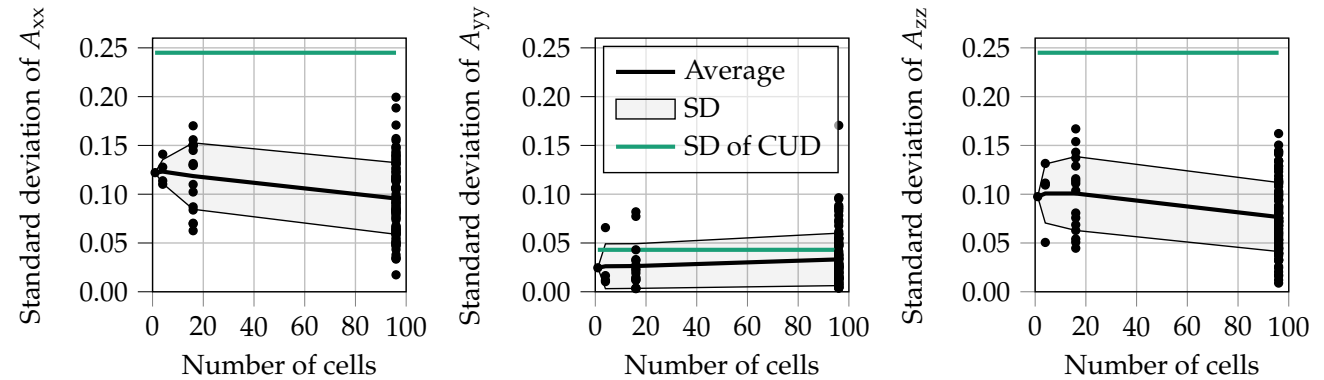

Figure 6. Standard deviations of fiber orientation components $A_{\mathrm{xx}}, A_{\mathrm{yy}}$ and $A_{\mathrm{zz}}$ of the back walls of Configuration A shown in Figure 5 for different evaluation meshes compared with the standard deviation of a continuous uniform distribution (green). The mean standard deviation of the fiber orientation component is displayed as a solid line, and the standard deviation of the standard deviation is drawn as gray area to indicate the scatter of the results.

According to the reasoning above, it is likely that the microstructure of each SMC stack is unique due to the macroscopically heterogeneous fiber bundle architecture of SMC and the multitude of fiber bundles in the stack. Considering the interactions between neighboring fiber bundles, which are determined by random processes due to the lack of 
scale separation, it may be concluded that the microstructure of each SMC part is unique as well. Following this line of reasoning, fiber matrix separation and fiber orientation would still feature significant scatter, even with an arbitrary number of repetitions.

\subsection{Fiber Volume Content}

This section shows the results of $\mu \mathrm{CT}$ and TGA of the thick coupons molded from an SMC with a nominal FVC of 36.6\%. The coupon walls are ordered from I on the left to VI on the right. Subsequently, the simultaneous consideration of $\mu \mathrm{CT}$ and TGA enables the holistic analysis of fiber matrix separation and defects.

\subsubsection{Configuration A}

In Configuration A, the initial charge is positioned underneath the honeycombs. Thereby, the initial SMC stack overlaps walls I to III. Thus, fiber bundles are transported into the ribbed structures after a short flow path.

The honeycomb shows FMS only in the top sections of some walls with small areas with few or no fiber bundles (see Figure 7). Hereby, FMS develops in different positions with varying severity. The variance in severity and the location of FMS highlights the statistical nature of phenomena such as FMS, that develop in the absence of scale separation. The fibers stay assembled in bundles during compression molding; therefore, individual fiber bundles can be identified in the $\mu \mathrm{CT}$ scan. This matches the findings of other investigators $[32,59,60]$ and confirms the assumption of the bundle approximation used for the Direct Bundle Simulation. Breakage of individual fibers or entire fiber bundles is not observed, which matches the findings of Trauth [66] and Motaghi [67]. The fiber bundles exhibit a strong curvature that results from complex interactions during mold filling. There are small cracks visible in matrix-rich sections. Only few pores can be seen in the junction of two adjacent walls.

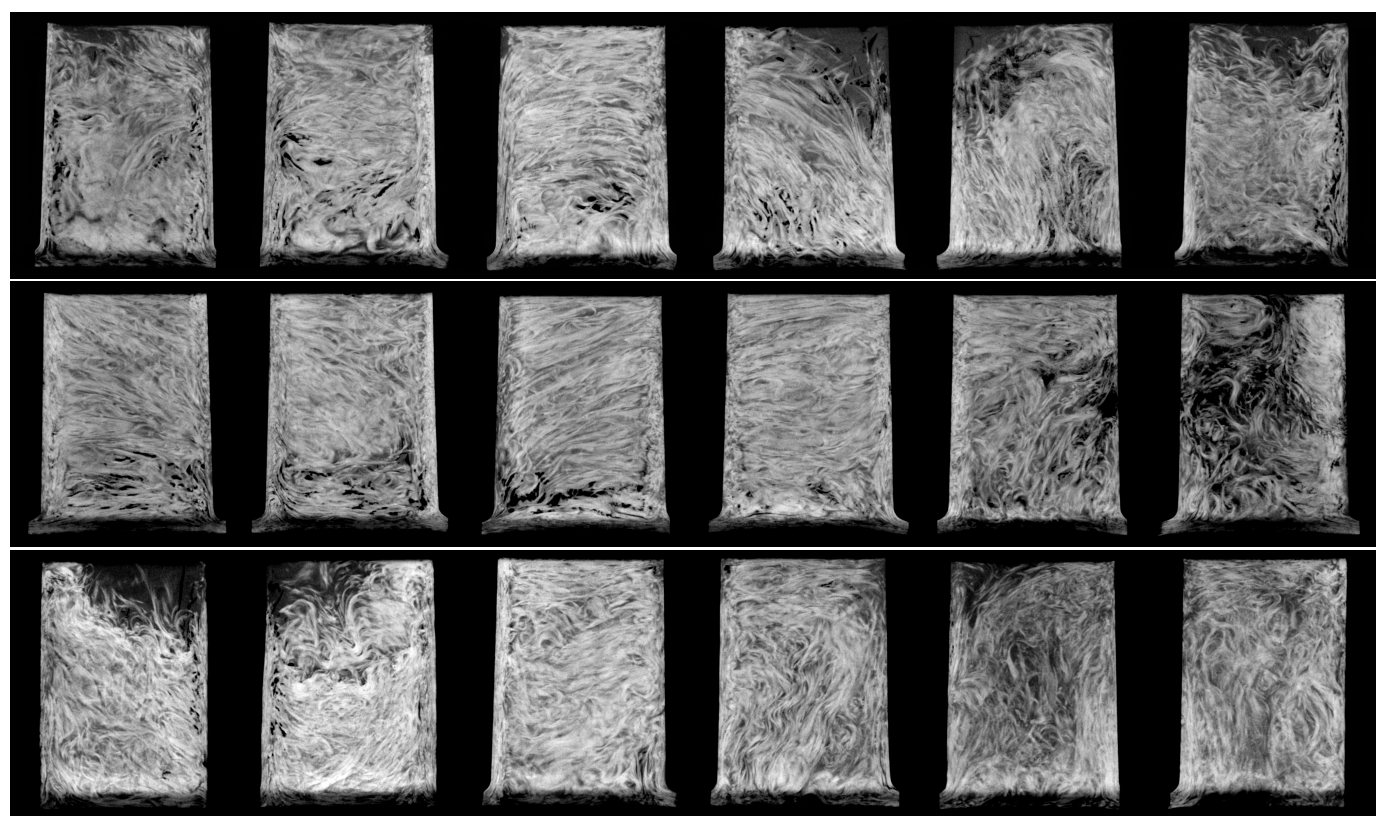

Figure 7. $\mu \mathrm{CT}$ scans of three coupons molded with Configuration A. The images in each row show the walls numbered I to VI from left to right (see Figure 1b).

Three samples from the same process configuration, but different specimens, are analyzed via thermal gravimetric analysis and the resulting average FVC is illustrated in Figure 8. In general, the honeycomb contains FVC that are similar to the nominal $36.6 \%$. The FMSI equals 0.06 for the results shown in Figure 8 . Here, the standard deviation is small compared with the average FVC of the individual sections. The small differences in FVC of adjacent sections could be an indication for locally occurring FMS, which is also visible in 
$\mu \mathrm{CT}$ scans of coupons molded with Configuration A (Figure 7). The thermal gravimetric analysis confirms that there is slight FMS in walls IV to VI, which do not overlap the area that is covered by the initial charge. The top sections of these ribs is filled later than the rest of the honeycomb. The matrix is likely heated during flow through the honeycomb structure and thereby its viscosity is lowered. Hence, the hydrodynamic force acting on the fiber bundles would decrease, which may facilitate the development of FMS.

\begin{tabular}{|c|c|c|c|c|c|c|}
\hline Top & $\begin{array}{c}33.7 \\
\pm 5.70\end{array}$ & $\begin{array}{c}40.3 \\
\pm 0.70 \\
\end{array}$ & $\begin{array}{c}39.2 \\
\pm 1.80 \\
\end{array}$ & $\begin{array}{c}31.7 \\
\pm 3.10\end{array}$ & $\begin{array}{c}27.8 \\
\pm 2.40\end{array}$ & $\begin{array}{c}32.0 \\
\pm 4.80\end{array}$ \\
\hline Center & $\begin{array}{c}36.4 \\
\pm 3.20\end{array}$ & $\begin{array}{c}36.8 \\
\pm 2.70\end{array}$ & $\begin{array}{c}38.7 \\
\pm 0.90\end{array}$ & $\begin{array}{c}33.5 \\
\pm 2.20\end{array}$ & $\begin{array}{c}35.8 \\
\pm 3.20\end{array}$ & $\begin{array}{c}35.9 \\
\pm 3.60\end{array}$ \\
\hline Base & $\begin{array}{c}39.7 \\
\pm 1.60\end{array}$ & $\begin{array}{c}39.6 \\
\pm 2.70\end{array}$ & $\begin{array}{c}39.2 \\
\pm 1.20\end{array}$ & $\begin{array}{c}35.4 \\
\pm 2.20\end{array}$ & $\begin{array}{c}36.8 \\
\pm 4.70\end{array}$ & $\begin{array}{c}37.7 \\
\pm 1.80\end{array}$ \\
\hline & I & II & $\begin{array}{c}\text { I } \\
\text { III }\end{array}$ & IV & l & $\begin{array}{c}\text { l } \\
\text { VI }\end{array}$ \\
\hline
\end{tabular}

Figure 8. Average FVC and standard deviations of three different samples molded with process Configuration A are analyzed via thermal gravimetric analysis. The partitioning follows the illustration in Figure 1b, where the red dotted lines indicate the separation between top, center and base of the coupons.

\subsubsection{Configuration $B$}

In Configuration $\mathrm{B}$, the initial charge is positioned opposite to the honeycombs. Thus, fiber bundles must flow over at least half the length of the base plate to reach the honeycomb structures.

Similar to Configuration A, a complex fiber bundle architecture is observed. Although the bundles have to flow a considerable distance and through complex geometries, fibers remain assembled in bundles during molding. The honeycomb shows pronounced FMS mainly in the downstream walls (see walls I to III in Figure 9). The severity of this FMS and the fiber orientation states vary notably between individual coupons. Again, this indicates that the development of FMS is affected by random processes.

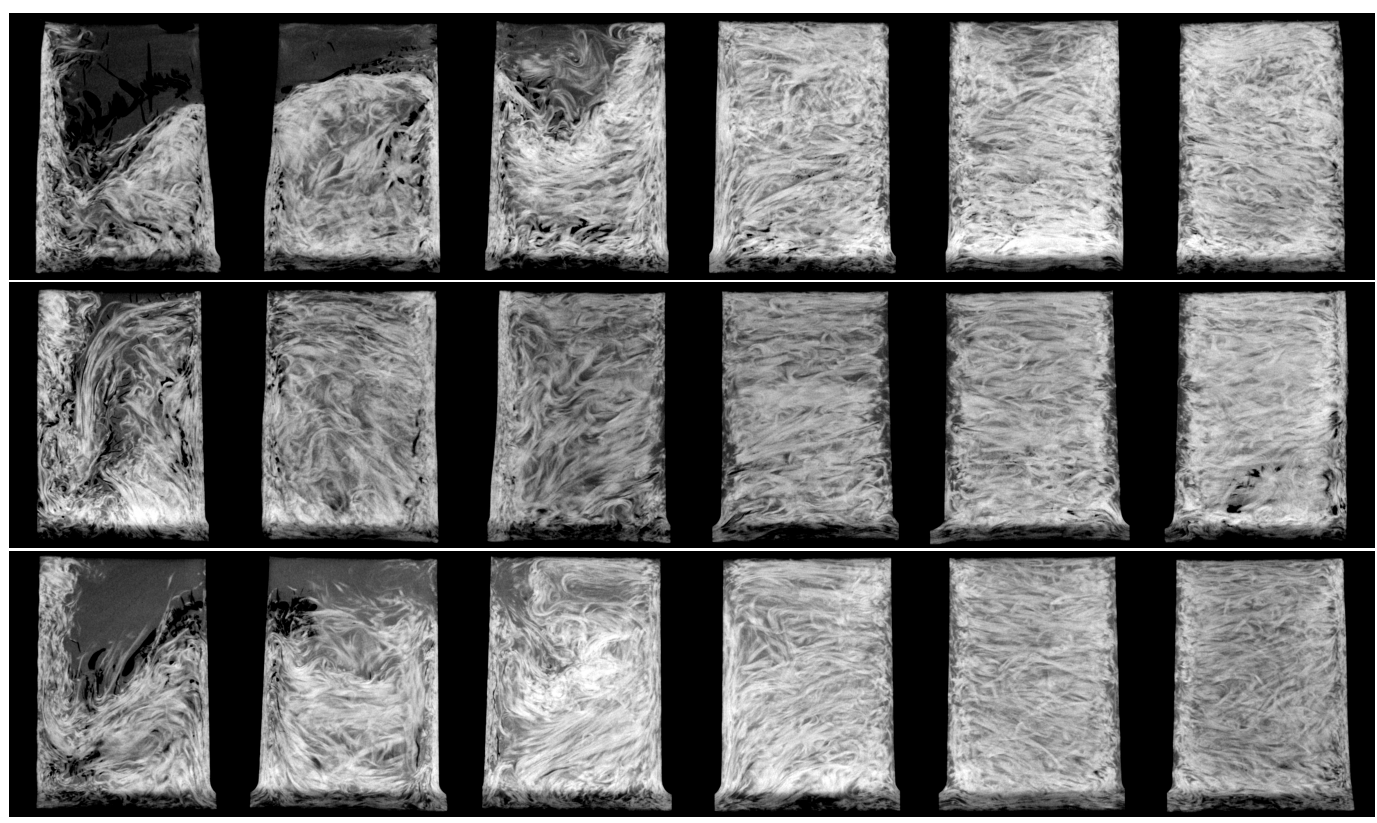

Figure 9. $\mu \mathrm{CT}$ scans of three coupons molded with Configuration B. The images in each row show the walls numerated I to VI from left to right.

Figure 10, which shows the TGA results for Configuration B, illustrates that the average FVC in the upstream walls is larger than the nominal FVC, while the average FVC 
in the downstream walls is lower than nominal. The occurrence of FMS in downstream walls most likely arises from fiber bundle jamming in the upstream walls. These walls are closest to the position of the initial charge in this configuration. Therefore, the SMC has to flow through these walls first to reach the downstream walls. The fiber bundles may jam along the flow path, thus hindering further fiber bundle transport and creating matrix-rich sections downstream. The FMSI equals 0.19 for the coupons shown in Figure 10 and is therefore more pronounced in the honeycomb molded with Configuration $B$ than in those molded with Configuration A.

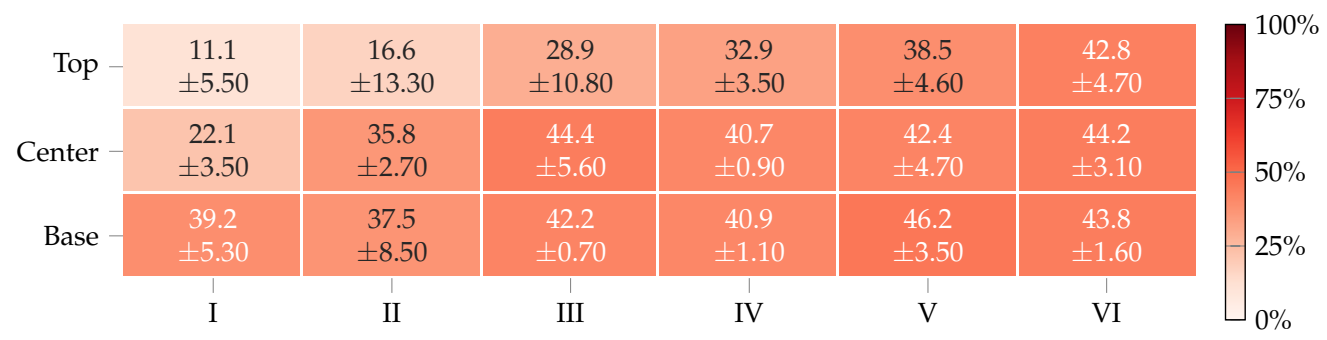

Figure 10. Average FVC and standard deviations of three different samples molded with process Configuration B are analyzed via thermal gravimetric analysis. The partitioning follows the illustration in Figure 1b, where the red dotted lines indicate the separation between top, center and base of the coupons.

It is also important to note that walls IV and VI both deviate from the direction of flow by the same angle but have significantly different FVC in the top sections. Thereby, wall VI is connected to two other walls, whereas wall IV is only adjacent to wall III. This suggests that neighboring walls limit or enable long fiber transport, depending on their number, position and orientation. Thus, it might not only be the geometry of the rib under consideration that matters, but also the ribs, walls and screw domes attached to it.

TGA and $\mu \mathrm{CT}$ indicate a large scatter of FVC between consecutive moldings in a wall, if the process configuration facilitates the development of FMS in this wall. Similar to the varying fiber orientation states in Section 5.4, this scatter might originate from a stronger dependence of the development of FMS on the initial bundle architecture in each stack. Thus, FVC in coupons molded with Configuration A are more reproducible than in coupons molded with Configuration B. A higher number of repetitions might be helpful to reliably determine the FVC in these configurations, but the question remains if sufficient reproducibility can be achieved even with an arbitrary number of repetitions.

\subsection{Fiber Bundle Architecture}

For a better understanding of the resulting fiber architecture, whole components are pyrolyzed to provide an overview of the fiber architecture in the honeycomb as well as in the base plate. The residue of the complete part after pyrolysis shows that fibers stay assembled in bundles during compression molding, which is in agreement with the $\mu \mathrm{CT}$ results shown above.

In Configuration A (see Figure 11a), the fibers to the left of the honeycombs are mainly oriented in the flow direction, which is likely the result of differently directed forces at the fiber ends. One end of these fiber bundles is pulled inside the honeycomb, while the other end is drawn in the flow direction. This results in the straightening and orientation of fiber bundles in the flow direction. Additionally, the flow front lags behind around the honeycombs because a lot of material flows into the honeycombs themselves. Hence, large velocity gradients emerge at the flow front, which in turn contribute to the reorientation of fiber bundles in the flow direction.

The residue of a honeycomb molded with Configuration B after pyrolysis shows that the peculiarity of FMS increases along the flow path (see Figure 11b). In the upper right cell, FMS is most pronounced and is visible with the bare eye. The dark gray clumps are mineral fillers which do not burn at the temperatures used for incineration. A weld line 
forms between the right edge of the base plate and the honeycomb from the material that flows around the honeycomb geometry. This shows that weld lines may form as the result of a complex rib geometry and not only due to the presence of multiple SMC stacks.
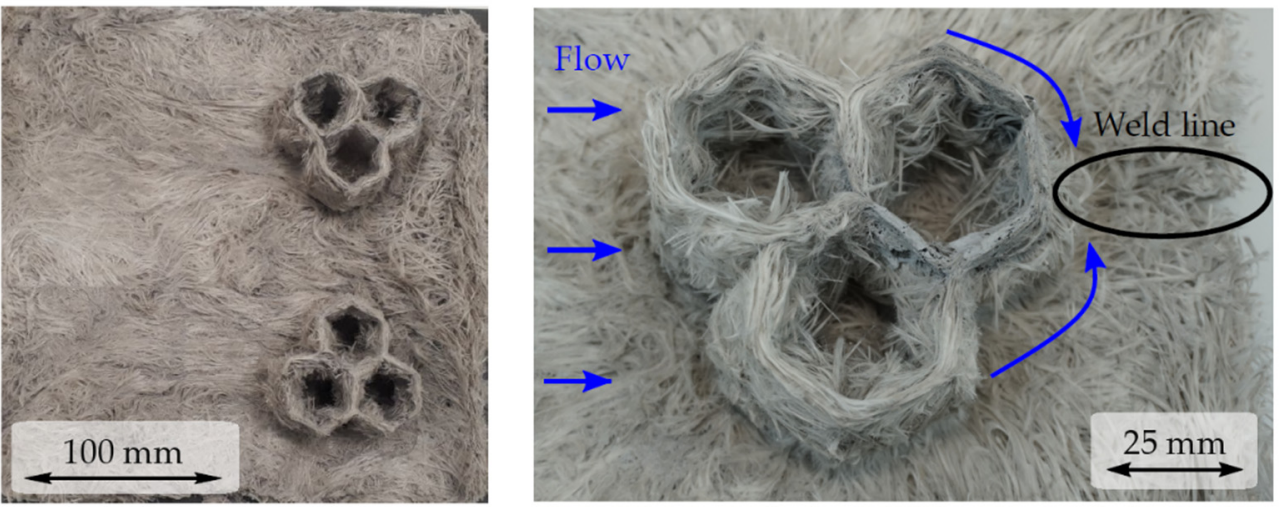

Figure 11. (a) Residue of the complete part molded with Configuration A after burning of the organic compounds. The thin and thick honeycombs are positioned in the lower and upper part of the picture, respectively. (b) Residue of a thick honeycomb molded with Configuration B after burning of the organic compounds. The coupon under consideration is the upper left cell.

\section{Numerical Results}

The following sections discuss the press data, the fiber volume content and fiber orientation in the thick honeycomb of Configurations A and B predicted by MOLDEX3D, MOLDFLOW, 3D TIMON and the Direct Bundle Simulation. The differences between experimental and numerical results are examined and explained in the context of the respective modeling approaches. Based on these results, the different process simulation methods are assessed.

\subsection{Compression Profile}

\subsubsection{Configuration A}

The simulation of Configuration A with MOLDEX3D predicts that the maximum compression force of $1500 \mathrm{kN}$ is reached almost immediately upon contact with the SMC stack (see Figure 12). This point is marked by a sudden drop of the compression velocity to roughly $0 \mathrm{~mm} \mathrm{~s}^{-1}$. The compression force remains constant for the rest of the molding while the compression velocity shoots up to $10 \mathrm{~mm} \mathrm{~s}^{-1}$. After a sudden drop, the compression velocity increases slowly up to $10 \mathrm{~mm} \mathrm{~s}^{-1}$ again and then drops back to $0 \mathrm{~mm} \mathrm{~s}^{-1}$ when the mold is closed almost completely. Afterwards, the compression force reaches $5 \mathrm{~mm} \mathrm{~s}^{-1}$ for a short time, during which the mold is closed completely.
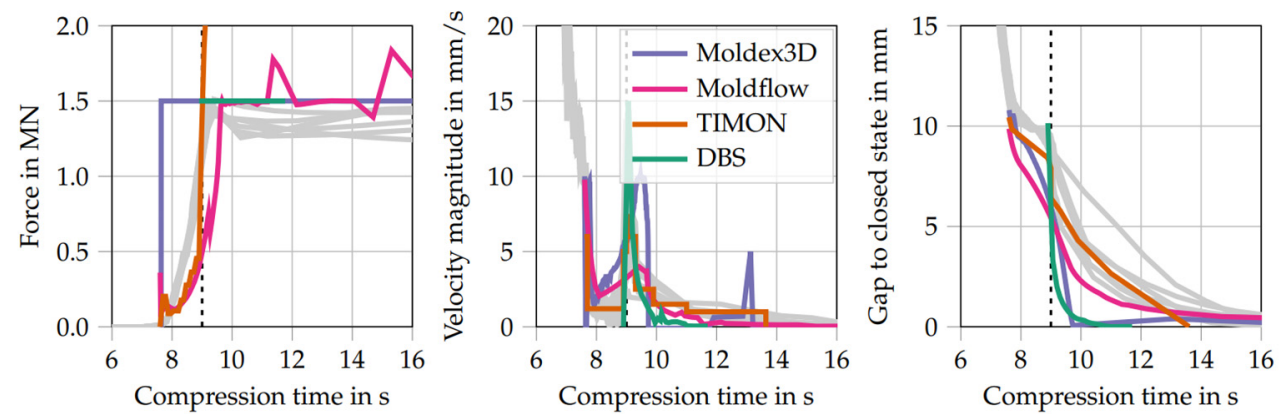

Figure 12. Press data from several parts molded with Configuration A (gray) compared with the numerical compression profiles predicted by MOLDEX3D (purple) and MOLDFLOW (pink), 3D TIMON (orange), and Direct Bundle Simulation (green). The dashed lines indicate the switch from displacement control to force control. 
The process simulation results from MOLDFLOW show for Configuration A a slight underestimation of the press force until the maximum press force is reached. After the maximum press force is reached, some problems with the press controller occur and the correct press force is not reached exactly. For the predicted closing speed profile, it can be observed that it matches the experimental data well. The combination of the underestimation of the press forces and the underestimation of the velocity peak point could be explained by the too-high compressibility of the used material, which has not been specifically characterized for this material. In comparison with the other simulation results, MOLDFLOW has the longest total compression time of approx. $16 \mathrm{~s}$. The gap prediction is therefore better compared with the other tools, but nevertheless overestimates the total compression time due to some problems with the press controller.

The compression profile of the half geometry molded with Configuration A shows that the compression force predicted by 3D TIMON $(15,670 \mathrm{KN})$ is about a factor of 10.4 higher than the force applied by the press on the full geometry during compression molding $(1500 \mathrm{kN})$. The reason for the discrepancy between experimental and numerical results is the no-slip boundary condition on the mold surface. Usually, the outer layers of SMC are heated by the mold and lubricate the surface with a thin layer of low-viscosity matrix. This alters the flow kinematics and decreases the shear stress in the outer layers of the SMC stack. Thus, the pressure needed to facilitate flow is reduced. Here, the no-slip boundary condition induces high shear stresses. Thereby, the pressure necessary for flow is increased. The jumps in the force profile reflect the discontinuities in the velocity profile, which can only be modeled as a series of constant velocities. This would require an infinitely large acceleration and force acting between each step of the compression profile and is a non-physical representation of the press profile.

In the Direct Bundle Simulation, the compression molding in Configuration A is modeled as the force-controlled closing of the mold with $1500 \mathrm{kN}$ due to the rapid stop of the physical press upon reaching the SMC stack. Here, the compression speed increases rapidly and decreases from there on until the mold is closed. The predicted compression time is significantly shorter than the actual compression time during compression molding due to the high initial closing speed. Employing the force boundary condition skips the initial pre-compression of the stack and saves computational time, but does not account for the rather small volume change in the stack due to the force application at this stage of the real process.

\subsubsection{Configuration B}

The simulation of Configuration B with MOLDEX3D predicts that the maximum compression force of $1500 \mathrm{kN}$ is reached almost immediately upon contact with the SMC stack (see Figure 13). Similar to the simulation of Configuration A, the compression velocity drops and increases several times before the mold is closed completely.

The process simulation results from MOLDFLOW show for Configuration B a similar behavior to that of Configuration A. The press force is slightly underestimated, until the maximum press force is reached. Nevertheless, the velocity and gap prediction matches the experiments quite well.

The compression profile of the half geometry molded with Configuration B shows that the compression force predicted by 3D TIMON $(15,270 \mathrm{KN})$ is about 10.2 times larger than the force needed by the press for the full geometry during compression molding $(1500 \mathrm{kN})$. This discrepancy and the jumps in the force profile can be explained by the same arguments as for Configuration A.

The Direct Bundle Simulation predicts that the compression force increases rather slowly upon contact with the SMC stack. Here, the velocity profile follows the actual compression velocity data of the press until it switches to force control. The velocity profile correctly shows a sudden decrease in compression velocity once the maximum force of $1500 \mathrm{kN}$ is reached. The predicted gap to closed state matches the press data well. The compression time predicted by the DBS is slightly shorter than the actual compression time. 

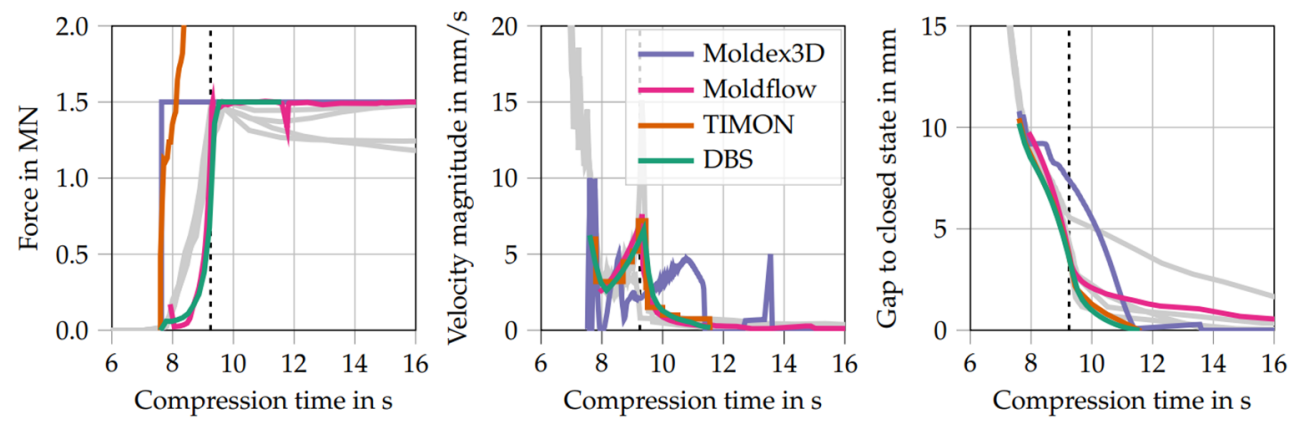

Figure 13. Press data from several parts molded with Configuration B (gray) compared with the numerical compression profiles predicted by MOLDEX3D (purple) and MoLDFLOW (pink), 3D TIMON (orange), Direct Bundle Simulation (green). The dashed lines indicate the switch from displacement control to force control.

\subsection{Fiber Volume Content}

\subsubsection{Configuration A}

MOLDEX3D predicts a uniform distribution of fibers in the honeycomb. Here, the FVC is equal to $44.8 \%$ (see Figure 14). Thus, the $\mathrm{FMSI}_{\text {Moldex3D,A }}$ equals 0.22 , which is about four times the experimental FMSI $\left(\right.$ FMSI $\left._{\mathrm{TGA}, \mathrm{A}}=0.06\right)$. Kuhn found similar results during his investigation of FMS with MOLDEX3D [14]. Here, rib base and rib top contained just a slightly different FVC, which also differed only marginally from the nominal FVC. The use of the FMSI might seem counter-intuitive because the FVC is basically the same, not only in the coupon but in the rest of the geometry as well. Nevertheless, the predicted FVC still deviates from the nominal FVC of $36.6 \%$ and the FMSI is employed to quantify the deviation from the nominal FVC.

MOLDFLOW was not considered within the investigations of the fiber volume content, since no model for fiber matrix separation is available. Even if it was not considered here, such a model could be implemented via the Solver API.

The DFS predicts an extreme FMS with low FVC in the top sections and an overall low FVC in walls II and V, which are oriented normal to the flow direction. The FMSI ${ }_{D F S, A}$ is roughly 0.75 which is about a factor of 12.5 larger than what is found by TGA (FMSI TGA,A $=$ 0.06). Here, the result clearly shows the weak point of disregarding fiber-fiber interaction in a directly modeled process simulation. Because fibers do not interact with one another, any number of them may be located at the exact same position. Thus, it is possible to obtain FVC that are higher than the theoretical maximum of a square packing (78.5\%) and hexagonal packing $(90.7 \%)$.

The DBS predicts a pronounced FMS in Configuration A. Here, FMSI ${ }_{\mathrm{DBS}, \mathrm{A}}$ is approximately 0.38 , which is about 6.3 times larger than what is found by TGA (FMSI TGA,A $=0.06$ ). The FVC in the top sections of walls IV, V and VI, which do not overlap the area, where the initial charge is placed, is lower than the nominal $36.6 \%$. This is qualitatively consistent with the results of TGA (see Figure 8). There are large differences between the FVC in directly adjacent walls, for example, the center section of wall III. Here, the FVC is $67.00 \pm 5.84 \%$ and therefore larger than the experimentally observed FVC in the rib base or any adjacent section. The FVC decreases from base to top which is expected during fiber bundle jamming. 
FVC - MOLDEX3D - Configuration A

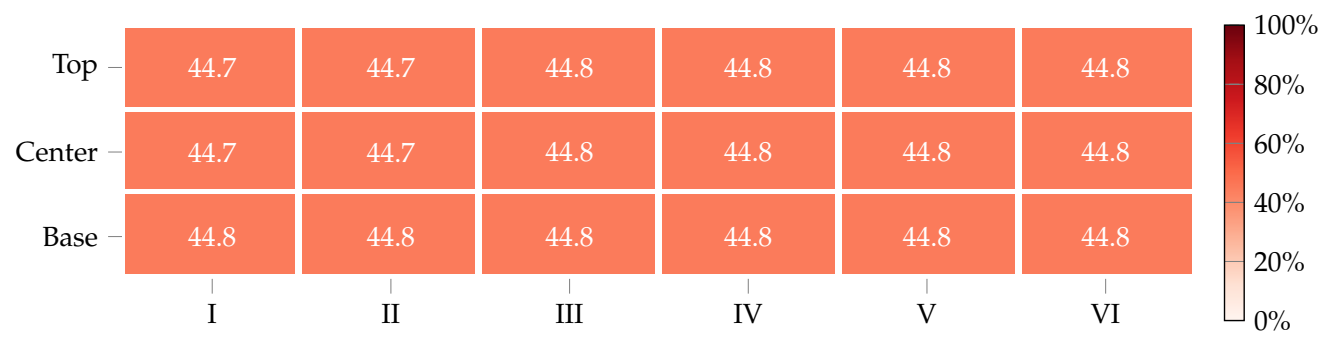

FVC - 3D TIMON - Configuration A

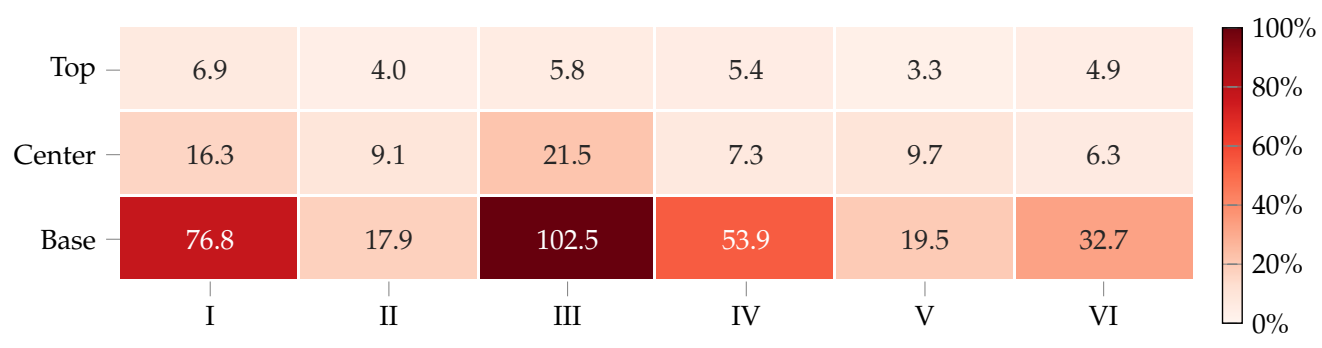

FVC - DBS - Configuration A

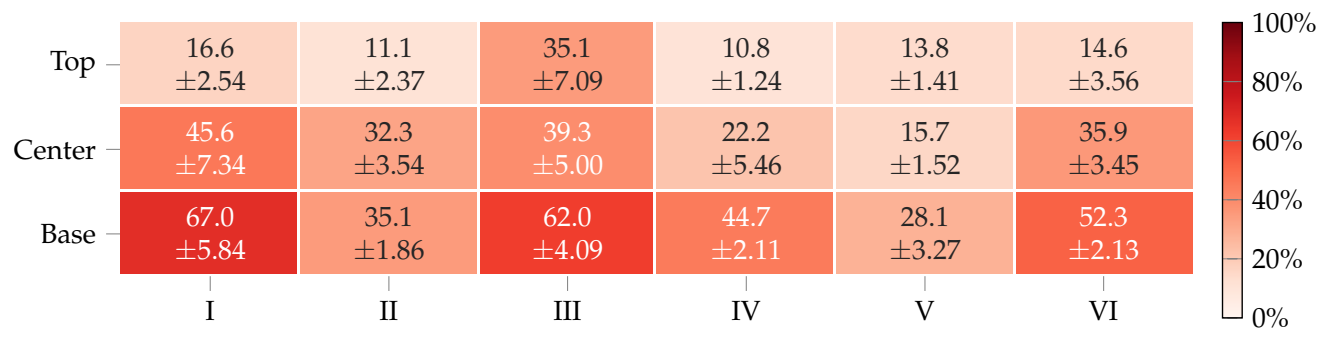

Figure 14. Fiber volume content of Configuration A according to MOLDEX3D, the Direct Fiber Simulation and the Direct Bundle Simulation. The experimental results are shown in Figure 8.

\subsubsection{Configuration $B$}

Similar to Configuration A, MOLDEX3D predicts a uniform FVC in Configuration B which is equal to $44.7 \%$ (see Figure 15). The FMSI Moldex3D,B equals 0.22 and is therefore similar to the FSMI which results from TGA $\left(\right.$ FMSI $_{\mathrm{TGA}, \mathrm{B}}=0.19$ ).

The DFS predicts an extreme FMS with low FVC in wall II which is oriented normal to the flow direction. Fibers get stuck in the base of walls I and III, thereby lowering the FVC in wall II. Interestingly, the top section of wall I contains a higher FVC than its base or any of the surrounding sections in wall VI. The FVC in the base of walls I and III is higher than the maximum of a hexagonal packing $\left(\phi_{\mathrm{f}, \text { hex,max }}=90.7 \%\right)$. The FMSI $I_{\mathrm{DFS}, \mathrm{B}}$ is about 0.60 , which is about 3.15 times larger than what is found by TGA $\left(\mathrm{FMSI}_{\mathrm{TGA}, \mathrm{B}}=0.19\right)$.

The DBS predicts a pronounced FMS in Configuration B with $\mathrm{FMSI}_{\mathrm{DBS}, \mathrm{B}}=0.34$, which is about 1.8 times larger than what is found by TGA (FMSI $\left.\mathrm{FGA}_{\mathrm{T}, \mathrm{B}}=0.19\right)$. Here, the walls that are located up the flow path, i.e., walls IV, V and VI, contain a higher than nominal FVC. This is qualitatively consistent with the results of $\mu \mathrm{CT}$ and TGA (see Figures 9 and 10).

However, $\mu \mathrm{CT}$ and TGA show that fiber bundle jamming increases the FVC in the rib base and up the flow path, whereas the FVC in the walls, which are located down the flow path, is decreased. Contrary to the results of $\mu \mathrm{CT}$ and TGA, the DBS predicts that wall II contains a low FVC and that wall I contains a high FVC. Therefore, the DBS predicts that the lowest FVC is found in the wall positioned closest to the end of the flow path. The FVC in the center of wall VI is $60 \%$. In contrast, the maximum FVC found by TGA in one coupon of Configuration B is $51.2 \%$. Therefore, the effect of fiber bundle jamming inside the ribbed structure is overestimated. 
FVC - MOLDEX3D - Configuration B

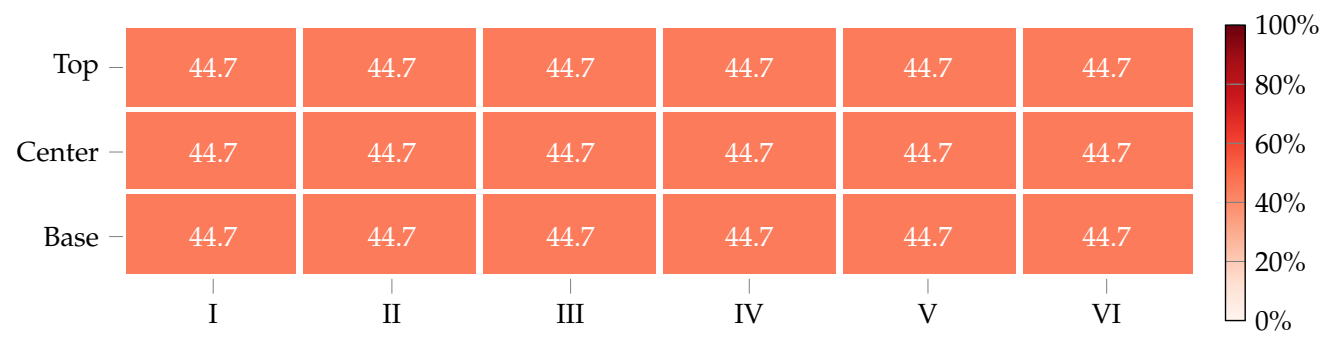

FVC - 3D TIMON - Configuration B

\begin{tabular}{|c|c|c|c|c|c|c|c|}
\hline Top & 68.9 & 10.7 & 45.5 & 20.4 & 6.3 & 19.7 & $60^{\circ}$ \\
\hline Center & 48.5 & 12.8 & 45.0 & 35.7 & 29.8 & 32.5 & $60 \%$ \\
\hline Base & 91.3 & 20.1 & 91.2 & 65.3 & 40.5 & 66.4 & \\
\hline & I & II & III & IV & V & VI & $0^{\circ}$ \\
\hline
\end{tabular}

FVC - DBS - Configuration B

\begin{tabular}{|c|c|c|c|c|c|c|}
\hline Top & $\begin{array}{c}32.6 \\
\pm 1.60\end{array}$ & $\begin{array}{c}9.8 \\
\pm 0.60\end{array}$ & $\begin{array}{c}50.1 \\
\pm 9.40\end{array}$ & $\begin{array}{c}46.8 \\
\pm 3.10\end{array}$ & $\begin{array}{c}44.4 \\
\pm 2.60\end{array}$ & $\begin{array}{c}53.5 \\
\pm 3.60\end{array}$ \\
\hline Center & $\begin{array}{c}54.0 \\
\pm 4.30\end{array}$ & $\begin{array}{c}24.9 \\
\pm 1.20\end{array}$ & $\begin{array}{c}50.2 \\
\pm 4.60\end{array}$ & $\begin{array}{c}48.2 \\
\pm 1.70\end{array}$ & $\begin{array}{c}37.8 \\
\pm 2.00\end{array}$ & $\begin{array}{c}60.4 \\
\pm 3.00\end{array}$ \\
\hline Base & $\begin{array}{c}54.6 \\
\pm 2.10\end{array}$ & $\begin{array}{c}42.5 \\
\pm 2.30\end{array}$ & $\begin{array}{c}47.9 \\
\pm 2.70\end{array}$ & $\begin{array}{c}47.7 \\
\pm 0.90\end{array}$ & $\begin{array}{c}44.5 \\
\pm 3.40\end{array}$ & $\begin{array}{c}52.2 \\
\pm 5.70\end{array}$ \\
\hline & I & II & $\begin{array}{c}\text { I } \\
\text { III }\end{array}$ & $\begin{array}{c}\text { I } \\
\text { IV }\end{array}$ & I & $\begin{array}{c}\mid \\
\text { VI }\end{array}$ \\
\hline
\end{tabular}

Figure 15. Fiber volume content of Configuration B according to MOLDEX3D, the Direct Fiber Simulation and the Direct Bundle Simulation. The experimental results are shown in Figure 10.

\subsection{Fiber Orientation}

The discrete orientation tensors of each cell of the evaluation mesh are rotated by an orthogonal orientation tensor $\mathbf{R}$ according to

$$
\tilde{\mathbf{A}}=\mathbf{R A R}^{\top},
$$

such that the coordinate system aligns with the wall orientation.

The evaluation of the normal component $\tilde{A}_{\mathrm{nn}}$ is shown in Figure 16. This component is of specific interest, because orientation normal to the walls is confined by the molds. It seems unreasonable that a significant portion of fiber bundles is aligned normal to the rib wall given their length of $50 \mathrm{~mm}$ and rib width of $2.5 \mathrm{~mm}$. This line of reasoning is confirmed by $\mu \mathrm{CT}$ fiber orientation analysis, which averages to $\tilde{A}_{\mathrm{nn}}=0.127 \pm 0.066$ in three samples. As discussed in Section 5.4, a detailed spatially resolved evaluation of fiber orientation tensors at this scale is questionable due to the scatter between individual realizations, but the overall average supports the statement that the out-of-plane component is small. 


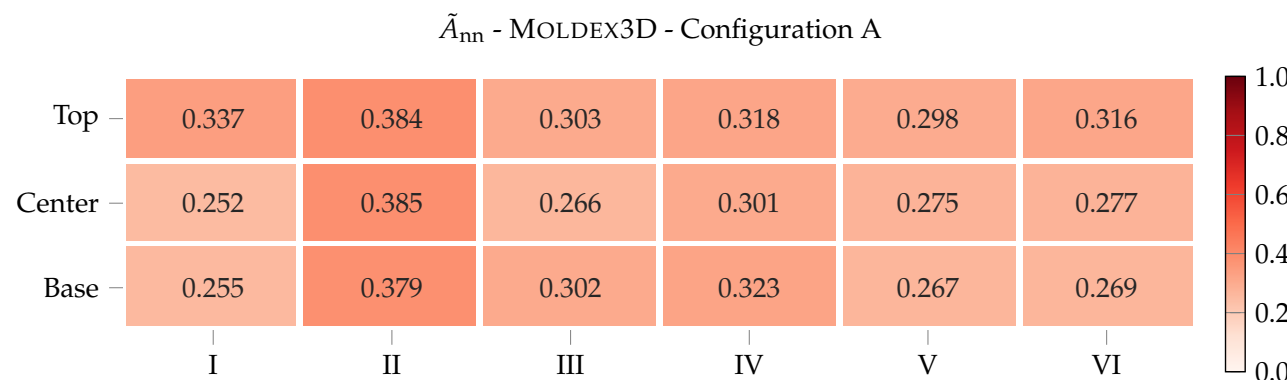

$\tilde{A}_{\text {nn }}$ - MOLDFLOW - Configuration A

\begin{tabular}{r|c|c|c|c|c|c|}
\hline Top -0.239 & 0.329 & 0.235 & 0.200 & 0.254 & 0.122 & 1.0 \\
\hline Center - & 0.252 & 0.381 & 0.260 & 0.217 & 0.261 & 0.133 \\
\hline Base - & 0.260 & 0.485 & 0.242 & 0.262 & 0.389 & 0.204 \\
I & II & III & IV & V & VI & 0.6 \\
0
\end{tabular}

$\tilde{A}_{\text {nn }}$ - DFS - Configuration A

\begin{tabular}{|c|c|c|c|c|c|c|}
\hline Top - & 0.080 & 0.086 & 0.066 & 0.068 & 0.094 & 0.071 \\
\hline Center - & 0.064 & 0.069 & 0.059 & 0.047 & 0.043 & 0.043 \\
\hline Base - & 0.112 & 0.250 & 0.120 & 0.078 & 0.109 & 0.083 \\
\hline & I & II & $\begin{array}{c}\text { I } \\
\text { III }\end{array}$ & IV & I & $\stackrel{\text { ' }}{\text { VI }}$ \\
\hline
\end{tabular}

$\tilde{A}_{\text {nn }}$ - DBS - Configuration A

\begin{tabular}{|c|c|c|c|c|c|c|}
\hline Top - & $\begin{array}{c}0.166 \\
+-0.017\end{array}$ & $\begin{array}{c}0.059 \\
+-0.030\end{array}$ & $\begin{array}{c}0.158 \\
+-0.020\end{array}$ & $\begin{array}{c}0.141 \\
+-0.010\end{array}$ & $\begin{array}{c}0.066 \\
+-0.015\end{array}$ & $\begin{array}{c}0.177 \\
+-0.014\end{array}$ \\
\hline Center & $\begin{array}{c}0.187 \\
+-0.012\end{array}$ & $\begin{array}{c}0.067 \\
+-0.010\end{array}$ & $\begin{array}{c}0.167 \\
+-0.006\end{array}$ & $\begin{array}{c}0.187 \\
+-0.014\end{array}$ & $\begin{array}{c}0.076 \\
+-0.020\end{array}$ & $\begin{array}{c}0.202 \\
+-0.021\end{array}$ \\
\hline Base & $\begin{array}{c}0.189 \\
+-0.040\end{array}$ & $\begin{array}{c}0.070 \\
+-0.008\end{array}$ & $\begin{array}{c}0.181 \\
+-0.013\end{array}$ & $\begin{array}{c}0.164 \\
+-0.033\end{array}$ & $\begin{array}{c}0.141 \\
+-0.016\end{array}$ & $\begin{array}{c}0.170 \\
+-0.011\end{array}$ \\
\hline & I & $\begin{array}{c}\text { | } \\
\text { II }\end{array}$ & $\begin{array}{c}\text { III } \\
\text { ches }\end{array}$ & $\begin{array}{c}\text { I } \\
\text { IV }\end{array}$ & I & $\begin{array}{c}\text { ' } \\
\text { VI }\end{array}$ \\
\hline
\end{tabular}

Figure 16. Normal components $\tilde{A}_{\text {nn }}$ of the rotated second-order fiber orientation tensor for Configuration A according to MOLDEX3D, MoldFlOW, the Direct Fiber Simulation and the Direct Bundle Simulation. The normal orientation component $\tilde{A}_{\text {nn }}$ should be small because fiber bundles are constrained by the plane of the surrounding walls.

However, both macroscopic models indicate a relevant component in the normal direction. This is a consequence of transporting the initial planar orientation state up to the ribs without sufficient reorientation and no consideration of the confinement by mold walls. The direct simulation models do account for interaction with the mold walls and thus the ability of fibers to orient normal to the ribs is limited. Hence, both direct models predict a reasonable normal component that is non-zero due to fiber curvature and bundles that protrude to different regions of the adjacent geometry. Configuration B leads to an equivalent conclusion and is therefore omitted here. Other orientation components are not compared, because the large scatter does not provide an unambiguous ground truth (see Section 5.4).

\subsection{Short Shots}

In addition to the comparison of press forces and fiber orientations, the flow front during the mold filling of Configuration A is also investigated by so-called short shots. For 
this purpose, spacers of $1.6 \mathrm{~mm}$ and $4.8 \mathrm{~mm}$ were inserted between the upper and lower mold, resulting in an incomplete filling. The resulting short shots were then measured three-dimensionally with an ATOS system by GOM to obtain a digital surface model. The digitized short shots with $1.6 \mathrm{~mm}$ and $4.8 \mathrm{~mm}$ spacers are compared with the predicted flow front at equivalent processing stages by means of a pictorial superimposition of the filling patterns (see Table 1).

Table 1. Comparison of scans of short shots (gray surfaces) to simulated flow front progression of the matrix phase (green) for Configuration A according to MOLDEX3D, MOLDfLOW, 3D TIMON and the Direct Bundle Simulation.

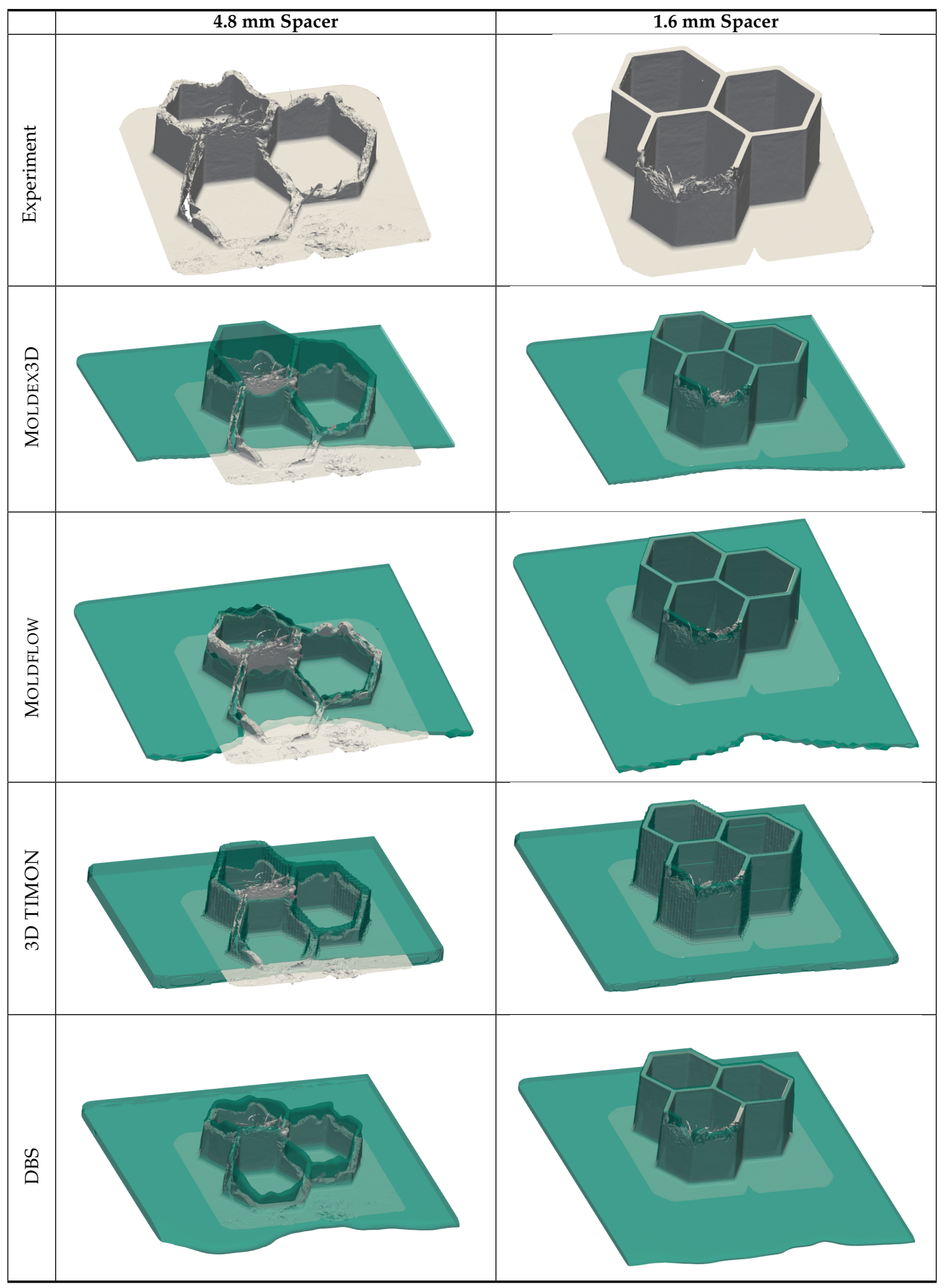


The short shot of the $4.8 \mathrm{~mm}$ experiment shows a uniform filling of the honeycomb walls. In particular, the initial stack's occupancy area (see Figure 1a) is evenly pressed into the honeycombs. A comparison with the simulation results shows that the uniform filling of the honeycomb walls at the rear could only be predicted by the MOLDFLOW $(4.8 \mathrm{~mm}$ spacer) and the DBS (4.8 mm spacer). The result of the MOLDFLOW calculation show a slight underestimation of the flow front progress, especially in the middle area, while the DBS tends to slightly overestimate the flow front. In general, however, the global filling pattern at this point is most accurately predicted by the DBS. The MOLDEX3D (4.8 $\mathrm{mm}$ spacer) and 3D TIMON (4.8 $\mathrm{mm}$ spacer) calculations both tend to have a gradient in the calculated flow front from the back to the front wall of the honeycomb. This is particularly evident in the MOLDEX3D result, where the rear area of the honeycomb is already completely filled, while the front area still shows no filling. A similar behavior, although not quite as pronounced, can also be seen in the results of the 3D TIMON simulation. Thus, these two methods do not represent the progress of the flow front sufficiently well at this point.

The short shot of the $1.6 \mathrm{~mm}$ experiment shows that the honeycomb geometry is already completely filled, except for one area in the front. This wall has an imperfection in the filling pattern, which can be explained by a fiber or scale separation effect. The fiber bundles, which are significantly longer than the filling structure, interact with each other and accumulate in the lower area of the honeycomb base.

This effect is matched very well by DBS $(1.6 \mathrm{~mm}$ spacer $)$ as both the location and the expression of the defect match the experiment most accurately at this point. 3D TIMON (1.6 mm spacer) also shows good agreement with the location of the resulting defect, but significantly underestimates it compared with the experiment. MOLDFLOW and MOLDEX3D (1.6 mm spacer) also show incomplete filling of the outer honeycomb wall. However, for both models the defect is predicted on the top of the outer honeycomb wall. In summary, this configuration was predicted very well by all investigated simulation methods within the respective model accuracy.

\section{Discussion}

\subsection{Compression Profile}

The compression profile predicted by MOLDEX3D compares well to the press data of Configuration A; however, there is a noticeable difference between the predicted and actual compression time in Configuration B. It is likely that the lack of differentiation between friction and viscous contributions during the rheological characterization of the SMC leads to a higher determined viscosity. This in turn increases the compression force or time needed for mold filling. Thus, it would be useful to characterize the friction and viscous contributions separately during press rheology.

The press force is quite well predicted by MOLDFLOW in both cases. The press force is slightly underestimated in the beginning, but fits quite well with the start of the compression cycle and the switching point. Furthermore, the predicted gap after the switching point is predicted well, only the problems with the press force controller lead to some misconceptions with the press force and thus the gap height.

As already mentioned in Section 6.1, the compression force predicted by 3D TIMON at the end of compression molding is several times larger than the maximum force. The velocity profile of 3D TIMON roughly approximates the actual compression velocity. Accordingly, the predicted gap to closed state matches the actual press data well. Thus, due to some modeling approaches, which can not be modified in the current version, 3D TIMON does not describe the SMC compression molding material behavior in a suitable way. Therefore, it would be helpful to implement boundary conditions, such as a wall friction model, that model its flow kinematics more accurately.

In Configuration A, the Direct Bundle Simulation overestimates the initial closing speed peak, because the simulation does not account for the pre-compaction of the material prior to the application of the constant compression force. Additionally, the applied compression force is higher than during the trials, since the press did not adhere to the 
prescribed maximum force during experiments. This results in a significant underestimation of the total compression time. In Configuration B, the compression force predictions of the Direct Bundle Simulation compare well to the press data. The total compression time is less underestimated than in Configuration A.

\subsection{Fiber Volume Content}

As shown in Section 5.5, the variation in the position of the initial charge induces FMS in various sections of the honeycomb. The uncertainty measure of FVC is larger, where severe FMS develops. The mechanism behind FMS is most likely fiber bundle jamming in walls along the flow path and the base of the walls. This matches the findings of Kuhn [14] who showed by experiment and simulation that fiber jamming is the driving mechanism behind FMS in ribbed structures made from long-fiber-reinforced polymers.

The macroscopic simulation tool MOLDEX3D predicts the FVC to be basically constant throughout the honeycomb. There is no distinctive distribution of fiber bundles inside the coupon as a result of mold filling. Thus, the fiber bundle jamming and the following development of matrix-rich sections is not replicated. Therefore, the statistical description of fiber-matrix interaction and fiber-mold interaction in macroscopically heterogeneous fiber suspensions might not be useful to predict FMS. The model used for the calculation of fiber volume content is based on a particle migration model introduced by Morris and Boulay [68]. It is a suspension balance equation which describes the flow of rigid spherical particles. It is questionable how such a model could describe the complex interactions between individual fibers or fiber bundles as well as between fiber bundles and the mold. Tseng et al. [69] validated the suspension balance model by comparing their prediction with the experimental work of Vélez-García et al. who investigated the FMS in a center-gated disk molded by injection molding [70,71]. However, the material used was a short-fiber-reinforced polymer and the geometry had no curvature, ribs or bosses. Therefore, the model used by MOLDEX3D might not be suitable for the simulation of fiber matrix separation during the compression molding of ribbed structures molded from long-fiber-reinforced polymers.

In contrast to MOLDEX3D, the Direct Fiber Simulation predicts a distinctive distribution of fiber bundles inside the coupon. Here, the fibers accumulate in the rib base and the FVC predicted by DFS are larger than the maximum FVC of a hexagonal packing. The key to answering the question of why there are high FVC in some walls is the DFS algorithm. As already stated, the DFS algorithm checks whether fibers are stretched above a certain threshold. Once the threshold is exceeded, the positions of the fiber nodes are recalculated. This is similar to a setback and fiber motion is impeded. Thus, fibers become stuck or are slowed down in flow situations in which the setback is triggered continually. One example of such a situation is complex ribbed structures, such as the honeycomb. Here, the setback is triggered because the fibers are pulled inside the honeycomb and at the same time in the flow direction.

The DBS shows a distinctive distribution of fiber bundles and the FVC predicted by the DBS is generally larger than what is found by TGA. The discrepancy between the experimental and predicted FVC in Configuration A during the pull-out of bundles might occur due to the modeling of the matrix as a Newtonian fluid, the viscosity of which does not depend on temperature. The DBS predicts in Configuration B that the fiber bundle jamming results in low fiber volume contents in wall II, which is positioned closest to the end of the flow path. However, the results of $\mu \mathrm{CT}$ and TGA show that wall I contains significantly less fiber bundles than wall II, although this measurement is accompanied by a large standard deviation.

\subsection{Fiber Orientation}

As already mentioned in Section 5.4, the fiber orientation states in honeycomb structures compression-molded from SMC feature significant scatter. Still, a statement can be made about the meaningfulness of the predicted fiber orientation components. Since the fiber 
bundles are $50 \mathrm{~mm}$ long and the wall only about $2.5 \mathrm{~mm}$ thick at the top, the fiber orientation component in the thickness direction should be relatively small. Thus, the fiber orientation should be dominated by the in-plane fiber orientation components.

MOLDEX3D and MOLDFLOW predict normal orientation components that are significantly larger than what is predicted by the directly modeled process simulations. This highlights that tensor-based fiber orientation models are not suited to simulate the orientation kinetics in fiber suspensions where there is a lack of scale separation. This could be addressed in the future by the incorporation of constraints in tensor-based models, for example, by following the work of [72]. In the DFS and DBS, fiber re-orientation depends on the modeled physics and not on the choice of fiber orientation model, closure approximation and interaction coefficient. Hence, the use of directly modeled process simulations is advantageous for the simulation of fiber orientation states in SMC components with confined geometric regions.

\subsection{Short Shots}

The results from the short shots in the $4.8 \mathrm{~mm}$ case show the influence of the wall friction used in the simulation model. The results of models, which use either no friction or a no-slip boundary condition, show a linear progression of the filling from the back wall of the honeycomb to the front. The models using a modified wall friction model (see Equations (3) and (6)) to represent the lubricating film between the material and the wall during manufacture show a more uniform filling of the honeycomb cavity, which provides a more realistic representation of the experimental results. In general, the DBS shows the best match of the filling pattern for the two investigated short shots. This underlines the necessity to accurately model the basic physical effects, such as fiber interactions or friction effects, when calculating the flow of highly filled long-fiber-reinforced polymers.

\subsection{Outlay and Benefit}

The characterization of thermo-rheological material parameters for the process simulation of long-fiber-reinforced materials is an elaborate and time-consuming process. Therefore, it is advantageous to employ simulation methods that produce acceptable results with a minimal number of material parameters. It is necessary to characterize the SMC viscosity for MoldeX3D, MOLDFLOW and the DFS. In contrast, the Direct Bundle Simulation needs only basic information about the initial FVC, fiber bundle geometry and matrix viscosity to run. However, there usually is no information about the rheological properties of the matrix of commercially available SMC materials. Furthermore, samples of the matrix material might not be provided by the SMC prepreg producer.

Unfortunately, the simulation run-times cannot be compared rigorously, because the computations are performed on different computers employing varying element types and spatial discretizations. Nonetheless, in general, the calculation run-times of directly modeled process simulations are usually longer than those of tensor-based models because of the additional calculation steps during the fiber simulation. Here, the DBS requires more computational resources than the DFS model due to the additional consideration of fiber interactions. Hence, tensor-based statistical models deliver results in a shorter time than directly modeled process simulations.

\section{Conclusions}

The predictive capabilities of different simulation approaches for the compression molding process of sheet molding compounds are evaluated and compared with experimental molding trials of a honeycomb structure with different process configurations. The assessment considers the compression profile as well as the fiber volume content and fiber orientation inside a confined region.

The development and severity of fiber matrix separation during the compression molding of sheet molding compounds is investigated experimentally by thermal gravimetric analysis and micro-computed tomography. Long flow paths facilitate fiber bundle jamming and the development of large matrix-rich sections. The fiber matrix separation index 
proved useful for the quantification and comparison of FMS in different configurations, as well as for the comparison between experimental and numerical results. Due to the macroscopically heterogeneous structure of sheet molding compounds, the location and severity of FMS and fiber orientation vary. Particularly in confined regions, the prediction quality of tensor-based models is considerably reduced, since fiber-fiber interactions, fiber-matrix interactions and fiber-mold interactions cannot be modeled explicitly.

Macroscopic process simulation tools are useful for a quick estimation of the mold filling pattern of ribbed structures. Combined with adequate material data, the compression profile can be predicted acceptably. Thus, macroscopic process simulations are valuable during the design phase. However, if the user is interested in the prediction of the fiber architecture in confined regions, a directly modeled process simulation should be preferred. They enable the simulation of local changes in fiber volume content. Additionally, directly modeled process simulation considers the constraint that is imposed on long fibers in confined regions by the mold. This leads to a more realistic out-of-plane fiber orientation component. However, the direct simulation of fibers requires more computational resources and calculation run-time than macroscopic process simulations.

Author Contributions: Conceptualization, F.R., N.M., S.W. (mold and material concept) and M.H.; methodology, F.R. (MOLDEX3D, 3D TIMON), N.M. (Direct Bundle Simulation), S.W. and M.H. (mold flow simulation); software, N.M.; validation, F.R. and S.W.; investigation, F.R. (molding trials, TGA), S.W. (molding trials, short shots) and M.H. (rheology); resources, F.R., N.M., S.W. and M.H.; data curation, N.M.; writing — original draft preparation, F.R.; writing — review and editing, N.M., S.W., M.H., M.G., F.H. and L.K.; visualization, F.R. and N.M.; supervision, M.G., F.H. and L.K.; project administration, S.W. All authors have read and agreed to the published version of the manuscript.

Funding: Parts of the research documented in this manuscript have been funded by the German Federal Ministry of Education and Research (BMBF) within the research project "Strukturelle Metall-KunststoffHybridbauweise am Beispiel eines Stoßfänger-Querträgers der elektrifizierten, automobilen GroßserieDarstellung eines wirtschaftlichen Herstellungsprozesses durch Integration einer On-Line-Qualitätssicherung und Optimierung der Materialausnutzung" (STYQZAHL). Parts of the research documented in this manuscript have been funded by the German Research Foundation (DFG) within the International Research Training Group "Integrated engineering of continuous-discontinuous long-fiber-reinforced polymer structures" (GRK 2078). Parts of the research documented in this manuscript have been funded by the state of Baden-Württemberg, Ministry of Science, Research and the Arts within the research project "VirtualSMC-Virtuelle Prozesskette für effiziente Ingenieuranwendungen von Sheet Moulding Compound". The support from the German Research Foundation (DFG), the Federal Ministry of Education and Research (BMBF) and the state of Baden-Württemberg is gratefully acknowledged.

Acknowledgments: We would like to thank TORAY ENGINEERING CO., LtD. and CORETECH SYSTEM CO., LTD. for providing their software tools for research and testing purposes.

We want to thank Apis mellifera for the groundbreaking work on efficient space filling with regular polygons.

Conflicts of Interest: The authors declare no conflict of interest.

\section{Appendix A. Parameters}

Table A1. Process parameters.

\begin{tabular}{lr}
\hline Process Parameter & Value \\
\hline Mold coverage & $25 \%$ \\
Mold temperature & $140{ }^{\circ} \mathrm{C}$ \\
Curing time & $240 \mathrm{~s}$ \\
Compression force & $1500 \mathrm{kN}$ \\
Compression speed & $10 \mathrm{~mm} \mathrm{~s}^{-1}$ \\
\hline
\end{tabular}


Table A2. MOLDEX3D and 3D TIMON parameters.

\begin{tabular}{lrr}
\hline Property & Symbol & Value \\
\hline Material specific constant & $B$ & $1 \times 10^{-2} \mathrm{Pas}$ \\
Reference temperature & $T_{\mathrm{b}}$ & $5.2 \times 10^{4} \mathrm{~K}$ \\
Power-law coefficient & $n$ & $8 \times 10^{-2}$ \\
Critical shear stress & $\tau^{*}$ & $1 \times 10^{1} \mathrm{~Pa}$ \\
\hline
\end{tabular}

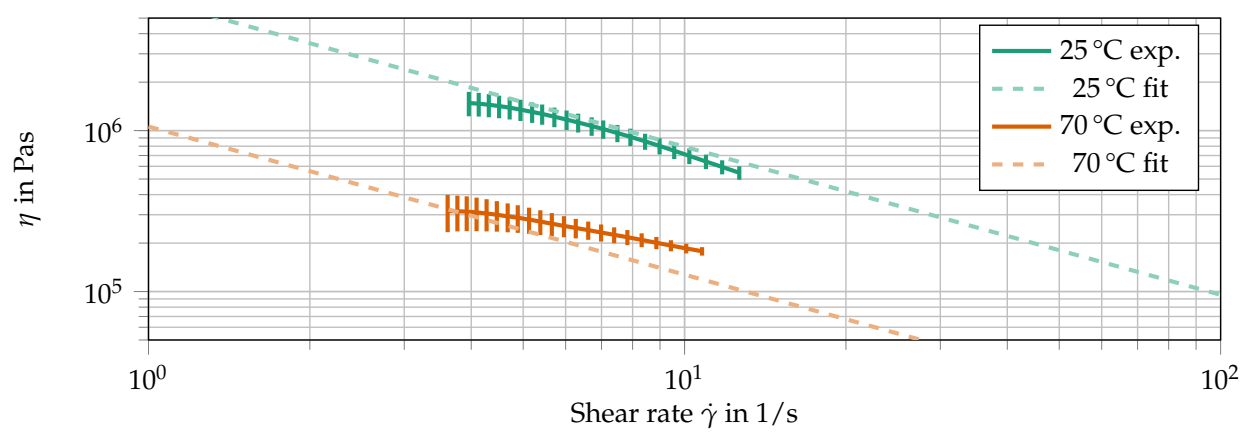

Figure A1. Average of the viscosity $\eta$ (solid lines) of three press rheometry samples vs. shear rate $\dot{\gamma}$ of the SMC at $T=25^{\circ} \mathrm{C}$ and $T=70^{\circ} \mathrm{C}$. The dashed lines indicate the viscosity function described by the Cross-Andrade model and the fit parameters shown in Table A2.

Table A3. $\mu \mathrm{CT}$ parameters.

\begin{tabular}{lr}
\hline Property & Value \\
\hline System & v I tome I x L450 \\
Target & Tungsten \\
Detector & GE DXR250 (CsI-scintillator) \\
Acceleration voltage & $220 \mathrm{kV}$ \\
Tube current & $220 \mu \mathrm{A}$ \\
Number of images & 2500 \\
Filter & $0.5 \mathrm{~mm} \mathrm{Cu}+0.5 \mathrm{~mm} \mathrm{Sn}$ \\
Voxel size & $72.9 \mu \mathrm{m}$ \\
\hline
\end{tabular}

Table A4. Direct bundle simulation parameters.

\begin{tabular}{lrr}
\hline Property & Symbol & Value \\
\hline Matrix viscosity & $\eta$ & $25,000 \mathrm{~Pa} \mathrm{~s}$ \\
Matrix mass density & $\rho_{\mathrm{r}}$ & $1300 \mathrm{~kg} \mathrm{~m}^{-3}$ \\
Bundle elastic modulus & $E$ & $73 \mathrm{GPa}$ \\
Bundle density & $\rho_{\mathrm{b}}$ & $2600 \mathrm{~kg} \mathrm{~m}^{-3}$ \\
Bundle radius & $R$ & $0.24 \mathrm{~mm}$ \\
Bundle segment length & $L$ & $2.5 \mathrm{~mm}$ \\
Mass scaling factor & $\kappa_{\mathrm{m}}$ & $1 \times 10^{4}$ \\
Hydrodynamic friction coefficient & $\lambda$ & $5.59 \mathrm{MN} \mathrm{s} \mathrm{m}^{-3}$ \\
Friction power-law coefficient & $m$ & 0.66 \\
Reference velocity & $v_{0}$ & $1 \mathrm{~mm} \mathrm{~s}^{-1}$ \\
\hline
\end{tabular}


Table A5. MOLDFLOW simulation parameters.

\begin{tabular}{lrr}
\hline Property & Symbol & Value \\
\hline Power-law coefficient & $n$ & 0.4 \\
Critical shear stress & $\tau^{*}$ & $0.1 \mathrm{~Pa}$ \\
Material specific constant & $B$ & $1.3261 \times 10^{18} \mathrm{Pas}$ \\
Reference temperature & $T_{\mathrm{b}}$ & $296.15 \mathrm{~K}$ \\
Wall slip coefficient & $\alpha_{\mathrm{w}}$ & $5.98 \times 10^{-11} \mathrm{~m} \mathrm{~Pa}^{-1} \mathrm{~s}^{-1}$ \\
Critical wall shear stress & $\tau_{\mathrm{w}}$ & $0 \mathrm{MPa}$ \\
Wall slip exponent & $m$ & 1.51515 \\
Wall slip temperature dependency & $b$ & $0 \mathrm{~K}^{-1}$ \\
Wall slip pressure dependency & $c$ & $0 \mathrm{~Pa}^{-1}$ \\
\hline
\end{tabular}

Table A6. Computational parameters.

\begin{tabular}{|c|c|c|c|c|}
\hline Property & Moldex3D & Moldflow & 3D TIMON & DBS \\
\hline Fluid elements & $2,322,404$ & $2,144,015$ & $1,066,411$ & $1,043,968$ \\
\hline Truss elements & - & - & $2,902,600$ & $\begin{array}{l}209,366 \\
213,527\end{array}$ \\
\hline Rigid elements & - & - & - & 67,740 \\
\hline CPU & $\begin{array}{l}\text { Intel(R) Xeon(R) } \\
\text { CPU E5-2690 v3 } \\
2.6 \mathrm{GHz}\end{array}$ & $\begin{array}{l}\text { Intel Xeon CPU } \\
\text { E5-2667 v2 (16 x } \\
3.3 \mathrm{GHz})\end{array}$ & $\begin{array}{l}2 \times \text { Intel Xeon } \\
61343.2 \mathrm{GHz}\end{array}$ & $\begin{array}{l}\text { AMD } \\
\text { EPYC 7302P }\end{array}$ \\
\hline RAM used & $128 \mathrm{~GB}$ & $\begin{array}{ll}192 & \text { GB } \\
\text { (available) }\end{array}$ & $128 \mathrm{~GB}$ & $15 \mathrm{~GB}$ \\
\hline $\begin{array}{l}\text { Computation } \\
\text { time }\end{array}$ & $40 \mathrm{~h}$ & $\begin{array}{l}54 \mathrm{~h} \text { to } 107 \mathrm{~h} @ 8 \\
\text { Cores }\end{array}$ & $31 \mathrm{~h}$ to $50 \mathrm{~h}$ & $\begin{array}{l}150 \mathrm{~h} \text { to } 200 \mathrm{~h} @ \\
16 \text { Cores }\end{array}$ \\
\hline
\end{tabular}

\section{References}

1. Ehrenstein, G.W.; Amesöder, S.; Fernandez, L.; Niemann, H.; Deventer, R. Werkstoff- und prozessoptimierte Herstellung flächiger Kunststoff-Kunststoff und Kunststoff-Metall-Verbundbauteile. In DFG Sonderforschungsbereich 396 Berichts- und Industriekolloqium 15./16. Oktober 2003; Geiger Manfred, E.G.W., Ed.; Meisenbach: Bamberg, Germany, 2003; pp. 149-178.

2. Kothmann, M.H.; Hillebrand, A.; Deinzer, G. Multimaterialkarosserien für batterieelektrische Fahrzeuge. Lightweight Des. 2018, 11, 10-17. [CrossRef]

3. Park, C.H.; Lee, W.I. Compression molding in polymer matrix composites. In Manufacturing Techniques for Polymer Matrix Composites (PMCs); Advani, S.G., Hsiao, K.T., Eds.; Woodhead Publishing Series in Composites Science and Engineering; Woodhead Publishing: Sawston, UK, 2012; pp. 47-94. [CrossRef]

4. Londono-Hurtado, A.; Osswald, T.A. Fiber jamming and fiber matrix separation during compression molding. J. Plast. Technol. 2006, 4, 1-17.

5. Eilbracht, S.; Londoño-Hurtado, A.; Osswald, T. Fiber orientation and fiber-matrix separation phenomena during compression molding. Annu. Tech. Conf.-ANTEC Conf. Proc. 2010, 2, 884-889.

6. Schemme, M. Sicherung der Produktqualität bei der Herstellung und Verarbeitung von SMC-Werkstoffen: Möglichkeiten und Grenzen. Ph.D. Thesis, University Erlangen-Nuremberg, Erlangen, Germany, 1996.

7. Dweib, M.A.; Vahlund, C.F.; Ó Brádaigh, C.M. Fibre structure and anisotropy of glass reinforced thermoplastics. Compos. Part A Appl. Sci. Manuf. 2000, 31, 235-244. [CrossRef]

8. Orgéas, L.; Dumont, P.; Michaud, V.; Favier, D. Separation of the polymer matrix and the fibrous reinforcement during compression moulding of Glass Mat Thermoplastics (GMT). Int. J. Mater. Form. 2008, 1, 929-932. [CrossRef]

9. Möbius, T.; Eilbracht, S.; Rudolph, N.; Osswald, T.A. Analyse zur Faserorientierung und Faser- Matrix-Separation bei einem Pressprozess mit kreisförmiger Fließfront. Z. Kunststofftechnik 2013, 9, 210.

10. Schmachtenberg, E.; Lippe, D.; Skrodolies, K. Faser/Matrix-Entmischung während des Fließpressens von SMC. Kunststofftechnik 2005, 1-15, 1-15.

11. Londoño-Hurtado, A.; Hernandez-Ortiz, J.P.; Osswald, T. Mechanism of fiber-matrix separation in ribbed compression molded parts. Polym. Compos. 2007, 28, 451-457. [CrossRef]

12. Christensen, S.K.; Hutchison, B.; Sun, E.M.; Osswald, T.A.; Davis, B.A. Fiber-matrix separation in ribbed SMC and BMC parts. In Technical Papers of the Annual Technical Conference-Society of Plastics Engineers Incorporated; Society of Plastics Engineers Inc.: Danbury, CT, USA, 1997; Volume 1; pp. 782-787.

13. Specker, O.; Osswald, T.A.; Michaeli, W. Methoden zur Vorausberechnung der Faserorientierung beim Pressen von SMC mit geschnittenen Glasfasern; Forschungsvereinigung Automobiltechnik EV (FAT): Frankfurt am Main, Germany, 1989. 
14. Kuhn, C. Analyse und Vorhersage von Faser Matrix Trennung während des Fließpressens von faserverstärkten Kunststoffen. Ph.D. Thesis, University Erlangen-Nuremberg, Erlangen, Germany, 2018.

15. Müller, S.; Florimond, C.; Trameçon, A. Crash and Statics Simulation of Short Fiber Reinforced Polymers in ESI Virtual Performance Solution Taking into Account Manufacturing Effects; SAE Technical Paper at WCX SAE World Congress Experience; SAE: Warrendale, PA, USA, 2019. [CrossRef]

16. Buck, F.; Brylka, B.; Müller, V.; Müller, T.; Hrymak, A.N.; Henning, F.; Böhlke, T. Coupling of Mold Flow Simulations with Two-Scale Structural Mechanical Simulations for Long Fiber Reinforced Thermoplastics. Mater. Sci. Forum 2015, 825-826, 655-662. [CrossRef]

17. Görthofer, J.; Meyer, N.; Pallicity, T.D.; Schöttl, L.; Trauth, A.; Schemmann, M.; Hohberg, M.; Pinter, P.; Elsner, P.; Henning, F.; et al. Virtual process chain of sheet molding compound: Development, validation and perspectives. Compos. Part B Eng. 2019, 169, 133-147. [CrossRef]

18. Jeffery, G.B. The motion of ellipsoidal particles immersed in a viscous fluid. Proc. R. Soc. London. Ser. A Contain. Pap. A Math. Phys. Character 1922, 102, 161-179. [CrossRef]

19. Einstein, A. Eine neue Bestimmung der Moleküldimensionen. Ann. Der Phys. 1906, 324, 289-306. [CrossRef]

20. Folgar, F.; Tucker, C.L. Orientation Behavior of Fibers in Concentrated Suspensions. J. Reinf. Plast. Compos. 1984, 3, 98-119. [CrossRef]

21. Advani, S.G.; Tucker, C.L. The Use of Tensors to Describe and Predict Fiber Orientation in Short Fiber Composites. J. Rheol. 1987, 31, 751-784. [CrossRef]

22. Wang, G.; Yu, W.; Zhou, C. Optimization of the rod chain model to simulate the motions of a long flexible fiber in simple shear flows. Eur. J. Mech.- B/Fluids 2006, 25, 337-347. [CrossRef]

23. Phelps, J.H.; Tucker, C.L. An anisotropic rotary diffusion model for fiber orientation in short- and long-fiber thermoplastics. J. Non-Newton. Fluid Mech. 2009, 156, 165-176. [CrossRef]

24. Tseng, H.C.; Chang, R.Y.; Hsu, C.H. An objective tensor to predict anisotropic fiber orientation in concentrated suspensions. $J$. Rheol. 2016, 60, 215-224. [CrossRef]

25. Tseng, H.C.; Chang, R.Y.; Hsu, C.H. Comparison of recent fiber orientation models in injection molding simulation of fiber reinforced composites. J. Thermoplast. Compos. Mater. 2020, 33, 35-52. [CrossRef]

26. Yamamoto, S.; Matsuoka, T. A method for dynamic simulation of rigid and flexible fibers in a flow field. J. Chem. Phys. 1993, 98, 644-650. [CrossRef]

27. Nyland, G.H.; Skjetne, P.; Mikkelsen, A.; Elgsaeter, A. Brownian dynamics simulation of needle chains. J. Chem. Phys. 1996, 105, 1198-1207. [CrossRef]

28. Ross, R.F.; Klingenberg, D.J. Dynamic simulation of flexible fibers composed of linked rigid bodies. J. Chem. Phys. 1997, 106, 2949-2960. [CrossRef]

29. Sasayama, T.; Sato, N.; Katagiri, Y.; Murayama, Y. Particle-level simulation for the prediction of short fiber orientation in injection molding. Compos. Part A Appl. Sci. Manuf. 2020, 139, 106115. [CrossRef]

30. Meyer, N.; Saburow, O.; Hohberg, M.; Hrymak, A.N.; Henning, F.; Kärger, L. Parameter Identification of Fiber Orientation Models Based on Direct Fiber Simulation with Smoothed Particle Hydrodynamics. J. Compos. Sci. 2020, 4, 77. [CrossRef]

31. Lindström, S.B.; Uesaka, T. Simulation of the motion of flexible fibers in viscous fluid flow. Phys. Fluids 2007, 19, 113307. [CrossRef]

32. Meyer, N.; Schöttl, L.; Bretz, L.; Hrymak, A.N.; Kärger, L. Direct Bundle Simulation approach for the compression molding process of Sheet Molding Compound. Compos. Part A Appl. Sci. Manuf. 2020, 132, 105809. [CrossRef]

33. DIN EN ISO 1172:1998-12; Textilglasverstärkte Kunststoffe-Prepregs, Formmassen und Laminate-Bestimmung des Textilglas- und Mineralfüllstoffgehalts. DIN Standards: Berlin, Germany, 1998. [CrossRef]

34. Cardarelli, F. Materials Handbook; Springer: London, UK, 2008. [CrossRef]

35. Rothon, R. Fillers for Polymer Applications; Springer International Publishing: London, UK, 2017. [CrossRef]

36. Castro, J.M.; Griffith, R.M. Sheet molding compound compression-molding flow. Polym. Eng. Sci. 1989, 29, 632-638. [CrossRef]

37. Dumont, P.J.J.; Orgéas, L.; Le Corre, S.; Favier, D. Anisotropic viscous behavior of sheet molding compounds (SMC) during compression molding. Int. J. Plast. 2003, 19, 625-646. [CrossRef]

38. Dumont, P.J.J.; Orgéas, L.; Favier, D.; Pizette, P.; Venet, C. Compression moulding of SMC: In situ experiments, modelling and simulation. Compos. Part A Appl. Sci. Manuf. 2007, 38, 353-368. [CrossRef]

39. Guiraud, O.; Orgéas, L.; Dumont, P.J.J.; Rolland du Roscoat, S. Microstructure and deformation micromechanisms of concentrated fiber bundle suspensions: An analysis combining x-ray microtomography and pull-out tests. J. Rheol. 2012, 56, 593-623. [CrossRef]

40. Hohberg, M.; Kärger, L.; Bücheler, D.; Henning, F. Rheological In-Mold Measurements and Characterizations of Sheet-Molding-Compound (SMC) Formulations with Different Constitution Properties by Using a Compressible Shell Model. Int. Polym. Process. 2017, 32, 659-668. [CrossRef]

41. Hohberg, M.; Kärger, L.; Henning, F.; Hrymak, A.N. Rheological measurements and rheological shell model Considering the compressible behavior of long fiber reinforced sheet molding compound (SMC). Compos. Part A Appl. Sci. Manuf. 2017, 95, 110-117. [CrossRef]

42. Hohberg, M. Experimental investigation and process simulation of the compression molding process of Sheet Molding Compound (SMC) with local reinforcements. Ph.D. Thesis, Karlsruhe Institute of Technology (KIT), Karlsruhe, Germany, 2019. [CrossRef] 
43. Schöttl, L.; Weidenmann, K.A.; Sabiston, T.; Inal, K.; Elsner, P. Fiber bundle tracking method to analyze sheet molding compound microstructure based on computed tomography images. NDT E Int. 2021, 117, 102370. [CrossRef]

44. Marker, L.; Ford, B. Flow and Curing Behavior Exhibited by SMC During Molding. Mod. Plast. 1977, 54, 64-66, 68, 70.

45. Barone, M.; Caulk, D. The effect of deformation and thermoset cure on heat conduction in a chopped-fiber reinforced polyester during compression molding. Int. J. Heat Mass Transf. 1979, 22, 1021-1032. [CrossRef]

46. Cardinaud, R.; Boyard, N.; Le Corre, S.; Sager, M. Quantitative analysis of a new SMC generation during compression moulding. In Proceedings of the ECCM18-18th European Conference on Composite Materials, Athens, Greece, 24-28 June 2018.

47. Teuwsen, J.; Hohn, S.K.; Osswald, T.A. Direct Fiber Simulation of a Compression Molded Ribbed Structure Made of a Sheet Molding Compound with Randomly Oriented Carbon/Epoxy Prepreg Strands-A Comparison of Predicted Fiber Orientations with Computed Tomography Analyses. J. Compos. Sci. 2020, 4, 164. [CrossRef]

48. Tseng, H.C.; Chang, R.Y.; Hsu, C.H. Phenomenological improvements to predictive models of fiber orientation in concentrated suspensions. J. Rheol. 2013, 57, 1597-1631. [CrossRef]

49. Chung, D.H.; Kwon, T.H. Invariant-based optimal fitting closure approximation for the numerical prediction of flow-induced fiber orientation. J. Rheol. 2002, 46, 169-194. [CrossRef]

50. Tseng, H.C.; Chang, R.Y.; Hsu, C.H. Numerical Predictions of Fiber Orientation and Mechanical Properties for Injection-Molded Long-Carbon-Fiber Thermoplastic Composites. Polym. Compos. 2018, 10, 3726-3739. [CrossRef]

51. Cintra, J.S.; Tucker III, C.L. Orthotropic closure approximations for flow-induced fiber orientation. J. Rheol. 1995, 39, 1095-1122 [CrossRef]

52. Bakharev, A.; Yu, H.; Speight, R.; Wang, J. Using New Anisotropic Rotational Diffusion Model to Improve Prediction of Short Fibers in Thermoplastic Injection Molding; Society of Plastics Engineers: Lubbock, TX, USA, 2018.

53. Kim, H.S.; Chang, S.H. Simulation of compression moulding process for long-fibre reinforced thermoset composites considering fibre bending. Compos. Struct. 2019, 230. [CrossRef]

54. Nakano, R.; Sakaba, K. Development of CAE Software for Injection and BMC/SMC Molding including Short/Long Fibers Reinforcement. In Proceedings of the International SAMPE Technical Conference, Paris, France, 10-11 March 2014.

55. Kuhn, C.; Koerner, E.; Taeger, O. A simulative overview on fiber predictions models for discontinuous long fiber composites. Polym. Compos. 2020, 41, 73-81. [CrossRef]

56. 3D TIMON 10: Reference Manual. 2019. Available online: https://www.3dtimon.com/\#/ (accessed on 6 August 2021).

57. Barone, M.R.; Caulk, D.A. Kinematics of flow in sheet molding compounds. Polym. Compos. 1985, 6, 105-109. [CrossRef]

58. Barone, M.R.; Caulk, D.A. A Model for the Flow of a Chopped Fiber Reinforced Polymer Compound in Compression Molding. J. Appl. Mech. 1986, 53, 361-371. [CrossRef]

59. Dumont, P.J.J.; Vassal, J.P.; Orgéas, L.; Michaud, V.; Favier, D.; Månson, J.A.E. Processing, characterisation and rheology of transparent concentrated fibre-bundle suspensions. Rheol. Acta 2007, 46, 639-651. [CrossRef]

60. Le, T.H.; Dumont, P.J.J.; Orgéas, L.; Favier, D.; Salvo, L.; Boller, E. X-ray phase contrast microtomography for the analysis of the fibrous microstructure of SMC composites. Compos. Part A Appl. Sci. Manuf. 2008, 39, 91-103. [CrossRef]

61. Motaghi, A.; Hrymak, A.N. Microstructure characterization in direct sheet molding compound. Polym. Compos. 2019, 40, E69-E77. [CrossRef]

62. Benson, D.J.; Okazawa, S. Contact in a multi-material Eulerian finite element formulation. Comput. Methods Appl. Mech. Eng. 2004, 193, 4277-4298. [CrossRef]

63. Meyer, N.; Hrymak, A.; Kärger, L. Modeling Short-Range Interactions in Concentrated Newtonian Fiber Bundle Suspensions. Int. Polym. Process. 2021, 36, 255-263. [CrossRef]

64. Shenoy, A.V. Rheology of Filled Polymer Systems; Springer Netherlands: Dordrecht, The Netherlands, 1999. [CrossRef]

65. Bronstein, I.N.; Semendjajew, K.A.; Musiol, G.; Mühlig, H. Taschenbuch der Mathematik, 10th ed.; Europa-Lehrmittel Nourney, Vollmer GmbH \& Co. KG: Haan-Gruiten, Germany, 2016.

66. Trauth, A. Characterisation and Modelling of Continuous-Discontinuous Sheet Moulding Compound Composites for Structural Applications. Ph.D. Thesis, Karlsruhe Institute of Technology (KIT), Karlsruhe, Germany, 2019. [CrossRef]

67. Motaghi, A. Direct Sheet Molding Compound process (D-SMC). Ph.D. Thesis, The University of Western Ontario, London, ON, Canada, 2018.

68. Morris, J.F.; Boulay, F. Curvilinear Flows on Noncolloidal Suspensions: The Role of Normal Stresses. J. Rheol. 1999, 43, 1213-1237. [CrossRef]

69. Tseng, H.C.; Wang, T.C.; Chang, Y.J.; Hsu, C.H.; Chang, R.Y. Progress on Fiber Concentration for Injection Molding Simulation of Fiber Reinforced Thermoplatics. In Proceedings of the ANTEC, Las Vegas, NV, USA, 28-30 April 2014.

70. Vélez-García, G.M.; Mazahir, S.M.; Wapperom, P.; Baird, D.G. Simulation of Injection Molding Using a Model with Delayed Fiber Orientation. Int. Polym. Process. 2011, 26, 331-339. [CrossRef]

71. Vélez-García, G.M.; Wapperom, P.; Baird, D.G.; Aning, A.O.; Kunc, V. Unambiguous orientation in short fiber composites over small sampling area in a center-gated disk. Compos. Part A Appl. Sci. Manuf. 2012, 43, 104-113. [CrossRef]

72. Pérez, C. The Use of Direct Particle Simulation to Predict Fiber Motion in Polymer Processing. Ph.D. Thesis, University of Wisconsin-Madison, Madison, WI, USA, 2016. 